\title{
Development of thin PdeAg supported membranes for fluidized bed membrane reactors including WGS related gases
}

\author{
Citation for published version (APA): \\ Fernandez Gesalaga, E., Helmi Siasi Farimani, A., Coenen, K. T., Melendez, J., Viviente, J. L., Pacheco \\ Tanaka, D. A., Sint Annaland, van, M., \& Gallucci, F. (2015). Development of thin PdeAg supported membranes \\ for fluidized bed membrane reactors including WGS related gases. International Journal of Hydrogen Energy, \\ 4O(8), 3506-3519. https://doi.org/10.1016/j.ijhydene.2014.08.074
}

DOI:

10.1016/j.jijhydene.2014.08.074

Document status and date:

Published: 01/01/2015

\section{Document Version:}

Publisher's PDF, also known as Version of Record (includes final page, issue and volume numbers)

\section{Please check the document version of this publication:}

- A submitted manuscript is the version of the article upon submission and before peer-review. There can be important differences between the submitted version and the official published version of record. People interested in the research are advised to contact the author for the final version of the publication, or visit the DOI to the publisher's website.

- The final author version and the galley proof are versions of the publication after peer review.

- The final published version features the final layout of the paper including the volume, issue and page numbers.

Link to publication

\footnotetext{
General rights

- You may freely distribute the URL identifying the publication in the public portal. follow below link for the End User Agreement:

www.tue.nl/taverne

\section{Take down policy}

If you believe that this document breaches copyright please contact us at:

openaccess@tue.nl

providing details and we will investigate your claim.
}

Copyright and moral rights for the publications made accessible in the public portal are retained by the authors and/or other copyright owners and it is a condition of accessing publications that users recognise and abide by the legal requirements associated with these rights.

- Users may download and print one copy of any publication from the public portal for the purpose of private study or research.

- You may not further distribute the material or use it for any profit-making activity or commercial gain

If the publication is distributed under the terms of Article $25 \mathrm{fa}$ of the Dutch Copyright Act, indicated by the "Taverne" license above, please 


\title{
Development of thin Pd-Ag supported membranes for fluidized bed membrane reactors including WGS related gases
}

\author{
Ekain Fernandez ${ }^{a, b, *}$, Arash Helmi ${ }^{b}$, Kai Coenen ${ }^{b}$, Jon Melendez ${ }^{a, c}$, \\ Jose Luis Viviente ${ }^{a}$, David Alfredo Pacheco Tanaka ${ }^{a}$, \\ Martin van Sint Annaland ${ }^{b}$, Fausto Gallucci ${ }^{b, *}$ \\ a TECNALIA Research \& Innovation, Mikeletegi Pasealekua 2, 20009 San Sebastián-Donostia, Spain \\ ${ }^{\mathrm{b}}$ Chemical Process Intensification, Department of Chemical Engineering and Chemistry, Eindhoven University of \\ Technology, Den Dolech 2, 5612AD Eindhoven, The Netherlands \\ c Chemical Engineering and Environmental Department, University of the Basque Country UPV/EHU, \\ C/ Alameda Urquijo s/n, 48013 Bilbao, Spain
}

\section{A R T I C L E I N F O}

\section{Article history:}

Received 29 May 2014

Received in revised form

15 July 2014

Accepted 5 August 2014

Available online 11 September 2014

\section{Keywords:}

Palladium membrane preparation

Membrane reactors

Fluidized bed

Membrane stability

\begin{abstract}
A B S T R A C T
This paper reports the preparation, characterization and stability tests of Pd-based thin membranes for fluidized bed membrane reactor applications. Various thin membranes have been prepared by simultaneous Pd-Ag electroless plating. A simple technique for sealing of the produced membranes is reported and discussed. The membranes have been characterized for single gas permeation, and afterwards used for permeation of mixtures of gases and under fluidization conditions. The membranes have shown very high permeation rates and perm-selectivity when used as permeators. When applied in fluidized bed reactors it has been found that the membranes are stable as long as no interaction between the fluidization catalyst and the membrane surface occurs. For some catalysts a strong chemical interaction between the catalyst and the membrane surface has been observed which caused a drastic decrease in the membrane flux.
\end{abstract}

Copyright @ 2014, Hydrogen Energy Publications, LLC. Published by Elsevier Ltd. All rights reserved.

\section{Introduction}

High purity hydrogen is required in many processes, such as semiconductor manufacturing, fuel cells applications, chemical industry, analytical instruments, computer and aerospace industries, recovery of radioisotopes of hydrogen in nuclear reactors [1]. On the other hand, hydrogen production and separation can be also exploited for precombustion (decarbonization) route for carbon capture and sequestration (CCS) from fossil-fuel fired power stations [2]. Most of the hydrogen $(>80 \%)$ is currently produced by steam reforming of natural gas in large multi-tubular fixed-bed reactors. In small-scale applications, partial oxidation reactions and auto-thermal reforming (combination of partial oxidation (exothermic) and steam reforming (endothermic))

\footnotetext{
* Corresponding authors. Chemical Process Intensification, Department of Chemical Engineering and Chemistry, Eindhoven University of Technology, Den Dolech 2, 5612AD Eindhoven, The Netherlands.

E-mail addresses: ekain.fernandez@tecnalia.com (E. Fernandez), f.gallucci@tue.nl (F. Gallucci). http://dx.doi.org/10.1016/j.ijhydene.2014.08.074

0360-3199/Copyright @ 2014, Hydrogen Energy Publications, LLC. Published by Elsevier Ltd. All rights reserved.
} 
are also considered. These reactions are (generally) equilibrium limited and produce a hydrogen-rich gas mixture containing carbon oxides and other by-products. The carbon monoxide can be converted to carbon dioxide producing more hydrogen via the Water Gas Shift (WGS) reaction where steam is introduced as reactant (Equation (1)). WGS is thermodynamically favored at low temperatures and kinetically favored at high temperatures. The traditional two-stage WGS process consists of a first reactor operated at $300-450{ }^{\circ} \mathrm{C}$ (to efficiently convert the biggest part of $\mathrm{CO}$ ) and a second reactor that works at lower temperatures at $200-300{ }^{\circ} \mathrm{C}$ to convert the last part of $\mathrm{CO}$.

$\mathrm{CO}+\mathrm{H}_{2} \mathrm{O} \leftrightarrow \mathrm{H}_{2}+\mathrm{CO} \quad \Delta \mathrm{H}=-41.1 \mathrm{~kJ} / \mathrm{mol}$

During the last few years more attention has being paid on hydrogen perm-selective membrane reactors operated with commercial ferrochrome based catalysts which can integrate the WGS reaction and in-situ extraction of ultra-pure $\mathrm{H}_{2}$ in one-stage and accordingly shift the equilibrium and thus intensify the process (improving yields and selectivities and reducing downstream separation costs, while also reducing the required reactor volume) [3]. New noble metal catalysts have been developed and have been tested in packed-bed membrane reactors. Results have shown that improving membrane characteristics enhances the reactor performance, but it would be more beneficial to develop a more active catalyst with higher activity to facilitate the use of thinner catalyst beds with a higher specific membrane area and lower concentration polarization across the catalyst bed. Most recently, fluidized bed membrane reactors have been introduced to overcome the mass transfer limitations prevailing in packed bed reactors because of their excellent gas-solid contact and heat and mass transfer characteristics [4,5]. However, these reactors have not been exploited yet for the WGS reaction.

Among the membranes for $\mathrm{H}_{2}$ separation, the Pd-based membrane shows the highest permeability and exclusive selectivity for $\mathrm{H}_{2}$ due to the unique permeation mechanism.

In order to achieve the hydrogen separation targets defined by the Department of Energy of the United States (DOE) [6], very thin $\mathrm{Pd}$ membranes (less that $5 \mu \mathrm{m}$ ) are required. In comparison to $\mathrm{Pd}$, it is well known that $\mathrm{Pd}-\mathrm{Ag}$ alloy membranes have higher $\mathrm{H}_{2}$ permeability up to $70 \%\left(\mathrm{Pd}_{77} \mathrm{Ag}_{23}\right)$ and are stronger against hydrogen embrittlement ( $\mathrm{PdH} \alpha-\beta$ transition at low temperature) [1]. Common dense metal layer deposition technologies include physical vapor deposition (PVD, including magnetron sputtering, thermal evaporation or pulsed laser evaporation), chemical vapor deposition (CVD or MOCVD) and electroless plating (ELP) [7]. The electroless plating (ELP) method is the most used method for the preparation of thin Pd-based membranes particularly with respect to operational flexibility, simple equipment, cost performance and applicability to non-conductive materials of any shape. Pacheco Tanaka et al. developed a method for the simultaneous plating of $\mathrm{Pd}-\mathrm{Ag}$ with the desired composition of metals [8]. This was achieved by uniform deposition of nanoparticles of Pd nuclei on the surface of the substrate and careful control of the composition of the plating solution; various $\mathrm{Pd}-\mathrm{Ag}$ ratios were prepared by this method and the $\mathrm{H}_{2}$ permeation properties observed were studied and related to the embrittlement phenomenon [9]; recently, the method was improved and a synchronized deposition of $\mathrm{Pd} / \mathrm{Ag}$ was obtained [10].

Thin Pd-based membranes are generally supported on porous substrates including stainless steel and ceramic materials of planar or tubular configuration [2]. Porous ceramics are the most common substrate material, owing to their excellent chemical stability. However, Pd-based membranes deposited on a ceramic support showed gas leak problems after some thermal cycles, due to the detachment of the Pd membrane layer that is deposited on the glass used to join ceramic dense and porous parts. The presence of leaks causes a decline in the hydrogen selectivity. The most promising sealing approach is based on using graphite. In some works, graphite gaskets were applied onto the faces of the two ends of the membrane tube [11,12], but the sealing is poorly gastight and the membrane can be easily broken by mechanical stress induced by the sealing compression. The membrane tube can be also sealed to a metal tube with connectors. The design of the connector is critical, because it should limit the pressing force and avoid damage to the thin membrane layer during operation $[13,14]$.

In this paper we will present results on $\mathrm{Pd}-\mathrm{Ag}$ alloy supported on alumina tubes. The $\mathrm{Pd}-\mathrm{Ag}$ membranes were prepared by simultaneous electroless plating. A membrane sealing procedure based on graphite ferrules and stainless steel connector was optimized to be able to connect the ceramic supported Pd-based membrane to dense metal tubes. These sealed membranes showed high hydrogen permeance and selectivity, in the order of the targets for DOE 2015. In addition, the resistance of the membranes to catalyst fluidization in novel fluidized bed WGS membrane reactors is investigated and discussed.

\section{Experimental}

\section{Membrane preparation}

Tubular alumina supports with an outside pore size of $100 \mathrm{~nm}$ were provided by Rauschert Kloster Veilsdorf. The supports have an external diameter of 10.0-10.5 $\mathrm{mm}$ and an internal diameter of $7 \mathrm{~mm}$. For proper handling during membrane preparation, the alumina porous tubes were cut and connected to dense alumina tubes (provided by OMEGA with $6 \mathrm{~mm}$ OD and $4 \mathrm{~mm}$ I.D.), one end was closed, using an enameled glass (ASF1761, Asahi Glass Co., Ltd.) as shown in Fig. 1. The glass was applied in the junction point between the porous and dense support and cures at $1000{ }^{\circ} \mathrm{C}$ in air for $30 \mathrm{~min}$ (heating rates of $4^{\circ} \mathrm{C} / \mathrm{min}$ from room temperature to $200{ }^{\circ} \mathrm{C}$ and then of $12{ }^{\circ} \mathrm{C} / \mathrm{min}$ to $1000^{\circ} \mathrm{C}$ ).

$\mathrm{Pd}-\mathrm{Ag}$ thin layers were deposited on the alumina tubes by using a simultaneous ( $\mathrm{Pd}$ and $\mathrm{Ag}$ ) electroless plating technique. Firstly, the surface of the alumina tube was activated by seeding it with Pd nuclei prior to electroless plating following the procedure reported by Pacheco et al. [8]. The surface completely turned black due to uniform covering of palladium nuclei. By this procedure, a large number of fine palladium particles were deposited on the surface. 


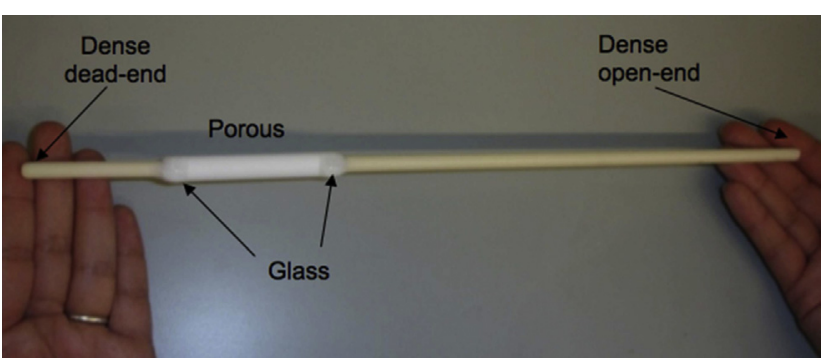

Fig. 1 - Assembled closed-end ceramic tubular support.

Pd and Ag were deposited by the simultaneous electroless plating method reported by Suzuki and Pacheco Tanaka [10]. The base plating process starts with the immersion of the activated alumina tube into a well stirred plating bath containing palladium acetate $(11.70 \mathrm{mM})$, silver nitrate $(0.64 \mathrm{mM})$, EDTA (0.15 M), ammonia (5 M) and hydrazine (15 mM). The whole system was placed in a thermostat bath maintained at 62-64 ${ }^{\circ} \mathrm{C}$. After $90 \mathrm{~min}$ of plating, a silver nitrate solution $(12.5 \mathrm{mM})$ was added at $0.117 \mathrm{ml} / \mathrm{min}$ in order to increase the Ag content of the membrane. The total time of the plating was $210 \mathrm{~min}$.

For some membranes, a second $\mathrm{Pd}-\mathrm{Ag}$ sequential plating step was carried out in order to have a thicker final membrane to prevent any possible membrane failure due to catalyst fluidization in contact with the membrane surface. In this case the plating bath was composed of palladium acetate (10 mM), silver nitrate (0.5 mM), EDTA (0.15 M), ammonia (5 M) and hydrazine (15 mM) (no additional adding of silver) and the plating deposition time was $30 \mathrm{~min}$.

The characteristics of the membranes produced and tested are shown in Table 1. The membrane designated with E15 has undergone only the base plating process and both E54 and E56 membranes have had two plating steps (the base plating and the second plating).

After each plating step, the membrane layers were annealed at $550{ }^{\circ} \mathrm{C}$ for $2 \mathrm{~h}$; this temperature should be above the maximum operating temperature, which is around $500{ }^{\circ} \mathrm{C}$ for the WGS membrane reactor, exposed to a $10 \% \mathrm{H}_{2} / 90 \% \mathrm{~N}_{2}$ gas mixture. The $\mathrm{Pd}-\mathrm{Ag}$ deposited alumina tubes were introduced into a quartz tube that was placed in a cylindrical furnace (from Termolab with a homogeneous heating length of $80 \mathrm{~cm}$ ). The temperature was increased at $3^{\circ} \mathrm{C} \mathrm{min}{ }^{-1}$ under nitrogen to the desired temperature and then heated at constant temperature. At $550^{\circ} \mathrm{C}$, a hydrogen flow of $50 \mathrm{~cm}^{3} \mathrm{~min}^{-1}$ and a nitrogen flow of $450 \mathrm{~cm}^{3} \mathrm{~min}^{-1}$ were fed into the furnace. Nitrogen was used for the cooling step.

Table 1 - Prepared Pd-Ag supported membranes $\left(\mathrm{Al}_{2} \mathrm{O}_{3}\right.$ $100 \mathrm{~nm}$ porous support of $10 \mathrm{~mm}$ outside diameter).

\begin{tabular}{lcc} 
Membrane code & Manufacturing method & Length $(\mathrm{mm})$ \\
\hline E15 & ELP (1 plating) & $36.3^{\mathrm{a}}$ \\
E54 & ELP (2 platings) & $68.0^{\mathrm{a}}$ \\
E56 & ELP (2 platings) & $74.6^{\mathrm{a}}$ \\
E62 & ELP (2 platings) & 50.0 \\
\hline
\end{tabular}

Membrane length after graphite attachment.

\section{Physico-chemical characterization of membranes}

The membrane E62 ( $\mathrm{Pd}-\mathrm{Ag})$ prepared with the same procedure as for E54 and E56 was used for as-prepared physicochemical characterization. The Pd and Ag contents of the membrane layer were determined by a Varian Vista MPX inductively coupled plasma optical emission spectrometer (ICP-OES). The cross-section images to analyze the morphology of the membrane layer and measure the membrane thickness were taken with an Environmental Scanning Electron Microscope (ESEM) (FEI Quanta 250 FEG). XRD of the membrane tube was measured with a Bruker D8 Advance to determine the alloying condition.

\section{Membrane sealing by graphite gaskets}

Sealing of Pd-based membrane layers deposited on ceramic tubular supports represents a challenging task: preliminary tests showed gas leak problems after some thermal cycles, due to the detachment of the Pd membrane layer that is deposited on the glass used to connect the ceramic dense and porous parts (see Fig. 2).

An extensive literature review was carried out in order to look for different options to solve this problem. Chen et al. [14] described a method using graphite ferrules instead of using standard metal ferrules. The authors have shown that these graphite ferrules could successfully seal the membrane with Swagelok ${ }^{\circledR}$ connectors. Even at very high pressures up to 50 bar, the nitrogen leakage rate over the connectors was only about $0.35 \mathrm{ml} / \mathrm{min}$.

To seal the membranes with Swagelok ${ }^{\circledR}$ fittings of $10 \mathrm{~mm}$ I.D. (code: SS-10M0-6), graphite ferrules of $10 \mathrm{~mm}$ I.D. (purchased from CHROMalytic TECH(nology) Pty Ltd) were used instead of the standard metal ones. Ferrules were opened from inside with a rotating cutter with sharp edges to increase the inner diameter of the ferrules in order to make them fit to the membranes (with an O.D. between 10 and $10.4 \mathrm{~mm})$.

Before sealing the membrane with the opened ferrules, the ferrules were first conditioned in the Swagelok ${ }^{\circledR}$ fitting with a dummy Stainless steel (316L) rod to form the ferrules to the right shape. The diameter of the dummy is equal to the diameter of the membrane to be sealed. The connectors were tightened with about 20-30 Nm (torque wrench) to form them with the right shape and to get a smooth inner surface (Fig. 3).

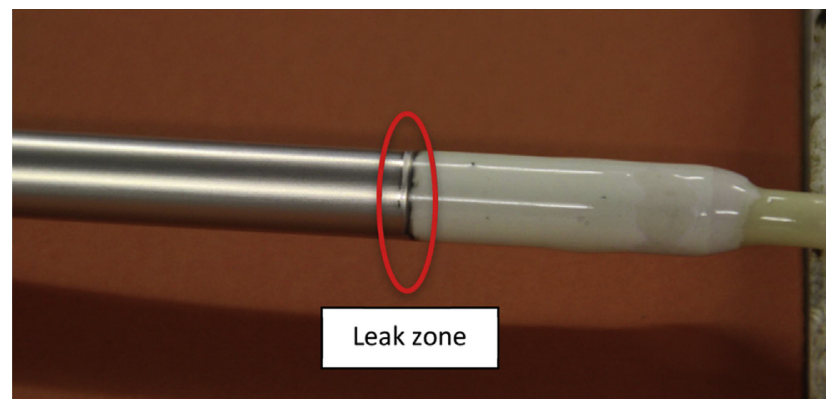

Fig. 2 - Leak zone of membranes found between Pd layer and glass used for join dense and porous parts after thermal cycles. 


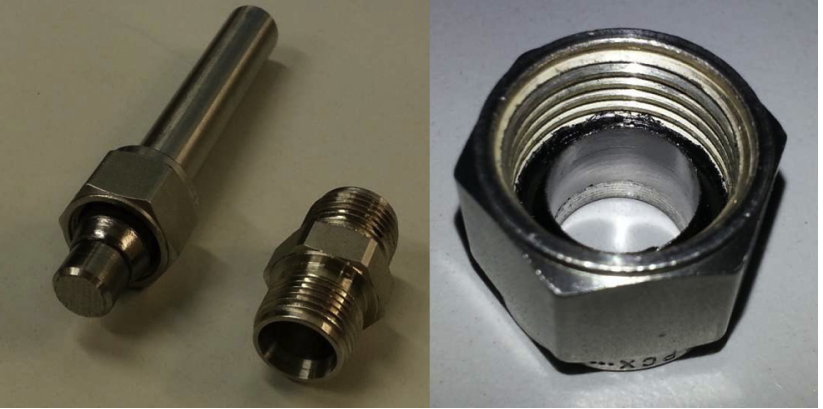

Fig. 3 - Left: 316L dummy rod with graphite ferrule and Right: connector with pre-treated ferrule (shiny inner surface).

After shaping the ferrules, the membrane was fitted to the connectors. The connectors were carefully tightened to the membrane with a torque wrench. First a torque of $5 \mathrm{Nm}$ was applied followed by increasing the force in two steps to $7 \mathrm{Nm}$. To verify whether the ferrules worked properly, Helium was fed from the inner part of the membrane up to a maximum pressure of 1 bar and introduced in a water bath. The formation of bubbles indicates that the connectors were not welltightened and should be tightened more in order to avoid leaks. If no bubbles were formed, it indicated that the connected membrane was well sealed (confirmed later by permeation tests) and could be implemented later in the test reactor.

A disadvantage of this sealing method is the loss of membrane area. For a membrane with nearly $137 \mathrm{~mm}$ length, the usable length of hydrogen permeation is about $105 \mathrm{~mm}$. The lost length because of the connectors is about $32 \mathrm{~mm}$ (in total for both sides). A typical membrane before and after

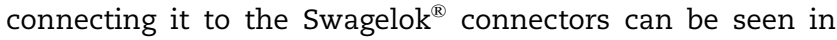
Fig. 4.

To further investigate the performance of the membrane sealing, a break test was carried out after the previous tests to determine the maximum tolerable torque on the membrane. The membrane was implemented in a new Swagelok ${ }^{\circledR}$ connector with a new graphite sealing. The graphite ferrules were treated as described before. The used torque for the sealing of the membrane was increased in steps from $1 \mathrm{Nm}$ to $15 \mathrm{Nm}$ to determine the breaking point of the membrane. At $14 \mathrm{Nm}$ the membrane support was broken.

As can be seen in Fig. 5, although the membrane broke at the exit of the Swagelok ${ }^{\circledR}$ connector, the cracks in the porous support actually started at the maximum load point of the graphite ferrule due to the excessive torque. For a proper sealing it is thus suggested to use the graphite ferrules and Swagelok $^{\mathbb{R}}$ with a maximum torque up to $8 \mathrm{Nm}$ to assure a very low level of leakage and prevent rupture of the ceramic support.

\section{Permeation characterization of membranes and sealing performance}

To test the applied sealing method, a membrane permeation setup was designed and constructed. Fig. 6 illustrates details
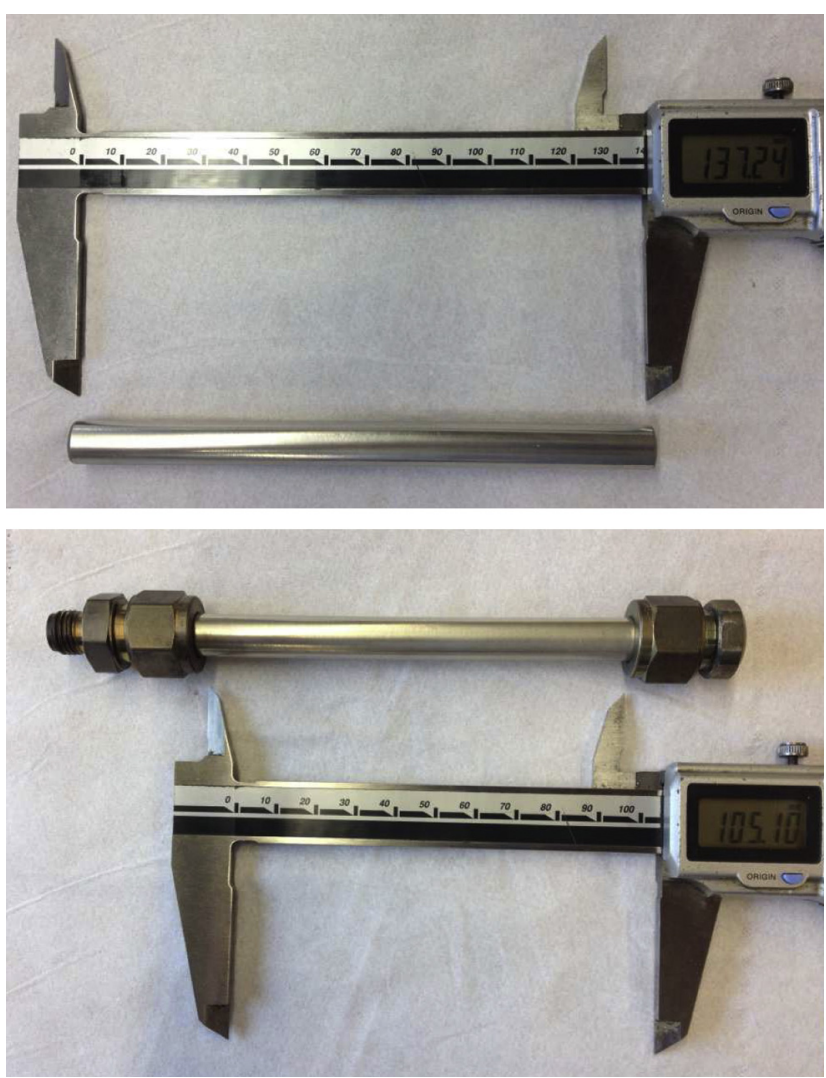

Fig. 4 - Pd membrane (E80 - Pd-Ag membrane, thickness 4.5 micron) before and after connecting to the Swagelok ${ }^{\circledR}$ connectors.

of the piping and instrumentation of the setup. The setup consists of three main sections: a feed section, a membrane module section and an analysis section. At the feed section mass flow controllers from BROOKS b.v. were used to set the desired gas composition $\left(\mathrm{N}_{2}, \mathrm{H}_{2}, \mathrm{CO}\right.$ and $\left.\mathrm{CO}_{2}\right)$ and flow rate.

The membrane module section consists of a stainless steel tube ( $3 \mathrm{~cm}$ i.d.) where the membrane is integrated from the top flange. The feed gas can be supplied to the module from the bottom part through a gas distributor. Thus, the module can also be used for fluidization tests. The whole membrane module (reactor) is placed in an electric furnace to be able to set the desired temperature inside the reactor (Fig. 7). Three temperature indicators were placed at different positions in

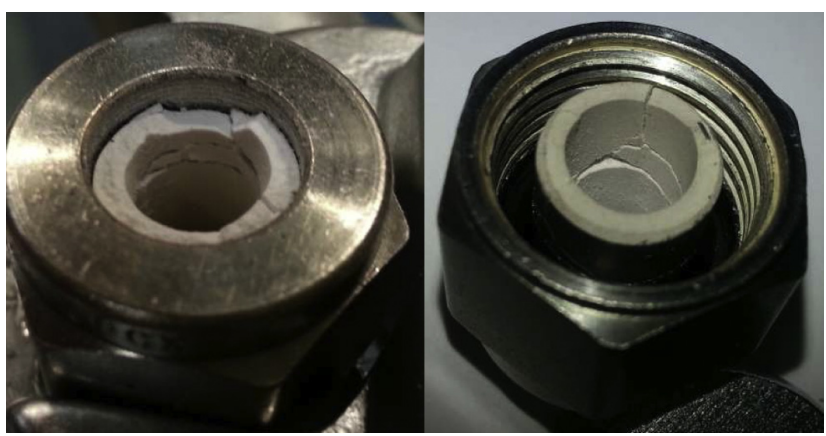

Fig. 5 - Broken Membrane after applying $14 \mathrm{Nm}$. 


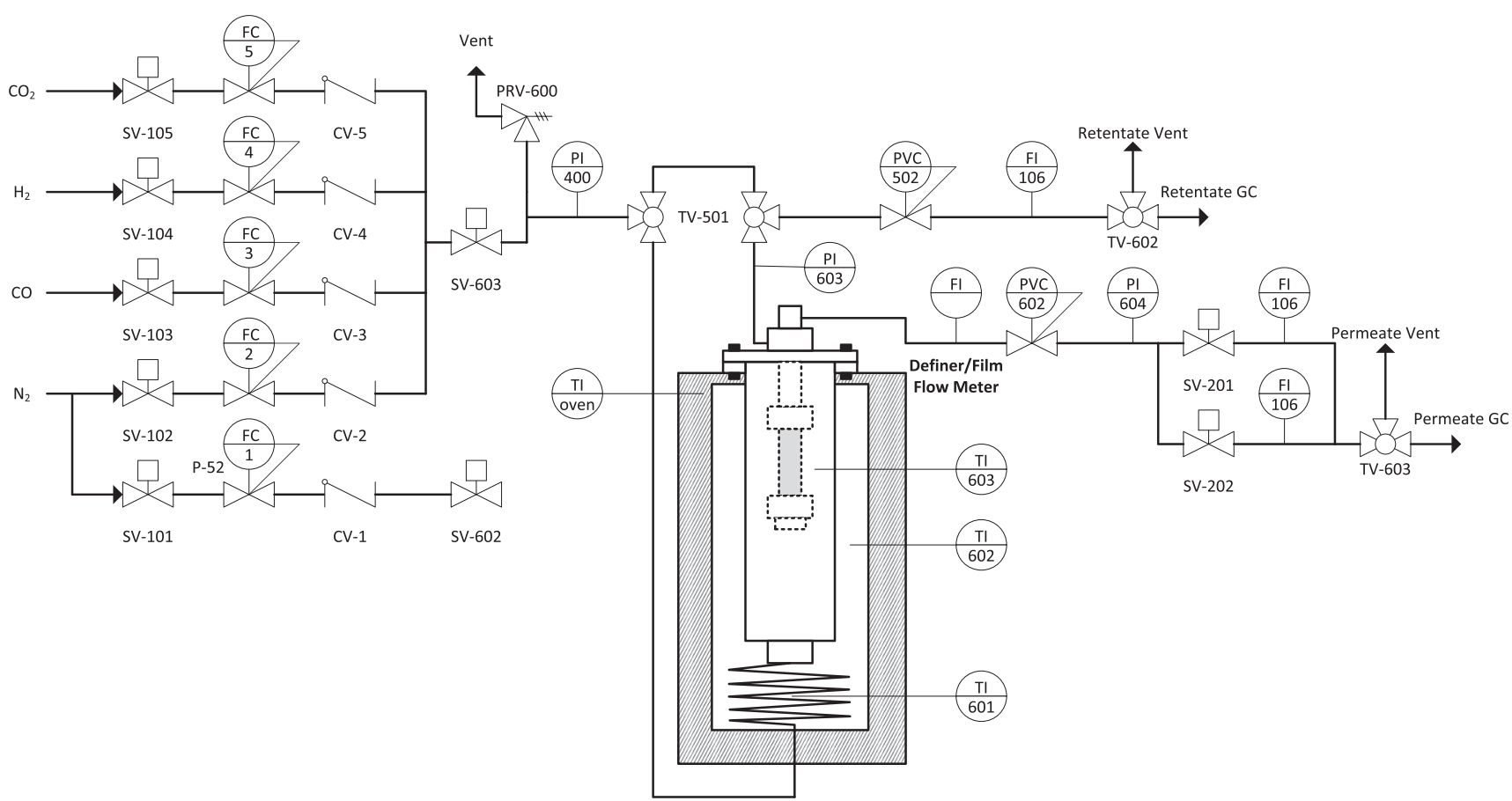

Fig. 6 - Process flow diagram for the permeation setup.

the module to measure and monitor the temperature. A backpressure regulator was placed at the outlet of the module (retentate side) to set the required trans-membrane pressure difference (two pressure indicators were placed at permeate and the retentate side). Both retentate and permeate sections were connected to the analysis section (independently). The analysis section consists of an HORIBA film flow meter (minimum $0.2 \mathrm{ml} / \mathrm{min}$ ) to measure the flow rate at the permeate side. At the retentate side a mass flow meter from BROOKS b.v. is placed. The outlet gases from both retentate and permeate sides can be analyzed with a $\mu$-GC (CP-4900 series from Varian b.v.) or directed to the vent.

First, permeation tests were carried out. Pure nitrogen (500 ml/min), pure hydrogen $(1000-1500 \mathrm{ml} / \mathrm{min}$ ) and $\mathrm{mix}$ tures of hydrogen and nitrogen were fed at different temperatures and pressures to the outside of the membrane and the permeation to the inner part of the membrane was quantified, while the inner part of the membrane was open to atmosphere and no sweep gas was used. For the permeation (leakage) of nitrogen, the Horiba Liquid Film Flow meter was used $(0.2-10 \mathrm{ml} / \mathrm{min})$. For the permeation of hydrogen two different Definer 550 (50-500 $\mathrm{ml} / \mathrm{min}$ or $300-30,000 \mathrm{ml} / \mathrm{min}$ ) were used depending on the hydrogen partial pressure.

The range of temperatures for the nitrogen permeation tests was between $20^{\circ} \mathrm{C}$ and $550^{\circ} \mathrm{C}$ and between $300^{\circ} \mathrm{C}-500^{\circ} \mathrm{C}$ for hydrogen. The permeance of hydrogen was measured at temperatures above $300{ }^{\circ} \mathrm{C}$ in order to prevent possible membrane embrittlement.

The stability of the sealing and the permeance performance were tested for these different cases:

- Long-time measurement for $\mathrm{N}_{2}$ and $\mathrm{H}_{2}$ (48 h test at $380-400{ }^{\circ} \mathrm{C}$ and 2 bar of pressure difference) to ensure the stability of the membrane and the sealing performance over a longer times.

- Thermal cycling test for $\mathrm{N}_{2}$ and $\mathrm{H}_{2}$ (heating up and cooling down of minimum 7 cycles from room temperature to $400^{\circ} \mathrm{C}$ ) to ensure that the sealing is not affected by thermal cycling possibly because of different expansion coefficients for the different materials (connectors, ferrules, membrane).

- Flow rate measurements for pure gas $\left(\mathrm{N}_{2}, \mathrm{H}_{2}\right)$ at different pressures and temperatures to determine the membrane permeation parameters.

- WGS feed mixture gas $\left(\mathrm{H}_{2}, \mathrm{~N}_{2}, \mathrm{CO}, \mathrm{CO}_{2}\right)$ at $400{ }^{\circ} \mathrm{C}$ to ensure that the sealing is not affected by chemical reactions with some of the used gases at reaction conditions.

- Implementation of the membrane in a fluidized bed (at room temperature and at $400{ }^{\circ} \mathrm{C}$ ) to ensure that the membrane works properly under fluidization conditions (using pure $\mathrm{N}_{2}$, mixture of $\mathrm{N}_{2} / \mathrm{H}_{2}$ and dry WGS mixtures).

- Because it was observed during experiments with membrane E15 that mass transfer limitations and or CO poisoning effect can be important for this type of membranes, experiments under different feed gas compositions of $\mathrm{H}_{2}$ to $\mathrm{N}_{2}$ ratios and also the addition of different amounts of $\mathrm{CO}$ were done for membrane E56.

- Post characterization of membrane surface.

A typical composition of a reformate gas fed to a WGS reactor is reported in Table 2 and used as reference case in this work. Because steam and methane were not available in the permeation setup and are also not necessary for the experiments, the feed composition for the WGS permeation tests in this work was changed to the composition listed in the third column. The total feed flow rate was about $1000 \mathrm{ml} / \mathrm{min}$. 


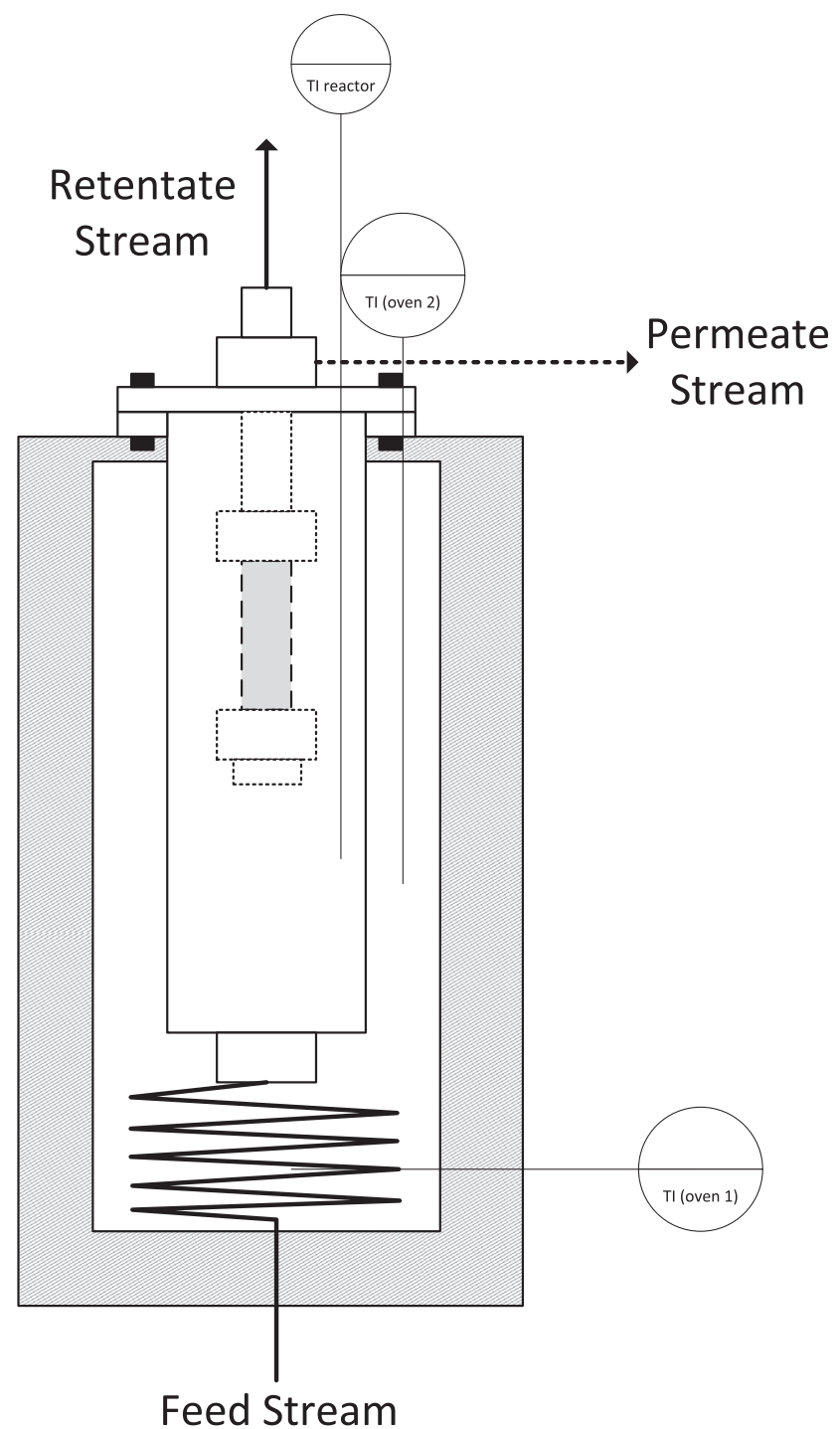

Fig. 7 - Details of the membrane reactor module including temperature and pressure indicators.

For the fluidization experiments, the gas flow rate was changed in such way that the bubbling fluidization conditions were maintained at different pressures and temperatures. All tested membranes and the tests carried out on each membrane have been summarized in Table 3 .

Because a strong performance loss (in terms of hydrogen permeance) was observed for Membrane E15 during the first fluidization tests, a more structured test campaign has been

\section{Table 2 - WGS gas feed composition.}

\begin{tabular}{lcc} 
Species & $\begin{array}{c}\text { Molar frac. (\%) } \\
\text { in industry }\end{array}$ & $\begin{array}{c}\text { Molar frac. (\%) used for } \\
\text { the permeation tests }\end{array}$ \\
\hline $\mathrm{CH}_{4}$ & 3.8 & - \\
$\mathrm{H}_{2}$ & 44.8 & 72.8 \\
$\mathrm{CO}$ & 9.2 & 14.6 \\
$\mathrm{CO}_{2}$ & 4.7 & 7.6 \\
$\mathrm{H}_{2} \mathrm{O}$ & 34.7 & - \\
$\mathrm{N}_{2}$ & 2.8 & 4.6 \\
\hline
\end{tabular}

Table 3 - Tests performed on different sealed membranes.

\begin{tabular}{lcccc}
$\begin{array}{l}\text { Membrane } \\
\text { code }\end{array}$ & $\begin{array}{c}\text { Pure } \\
\text { gas exp. }\end{array}$ & $\mathrm{H}_{2} / \mathrm{N}_{2}$ & Fluidization & $\begin{array}{c}\text { WGS } \\
\text { mixture }\end{array}$ \\
\hline E15 & $\mathrm{X}$ & $\mathrm{X}$ & $\mathrm{X}$ & $\mathrm{X}$ \\
E54 & $\mathrm{X}$ & & $\mathrm{X}$ & \\
E56 & $\mathrm{X}$ & $\mathrm{X}$ & $\mathrm{X}$ & $\mathrm{X}$ \\
\hline
\end{tabular}

carried out on the membranes E54 and E56 to further investigate the cause of this loss in performance. E54 was tested with pure gas and in fluidized conditions only to assess the effect of fluidization. The other membrane were tested with the complete test protocol.

\section{Results and discussions}

Physico-chemical characterization results of as-prepared Pd-Ag supported membranes

ICP

The Pd and Ag composition of two pieces of the same membrane layer (E62) was analyzed by ICP-OES. First, the two samples were dissolved using concentrated nitric acid and then diluted to be able to analyze in a proper way. The Ag content of the E62 membrane layer is $13.4 \pm 0.2 \%$.

\section{SEM-EDX}

The cross-section SEM image of the E62 membrane consisting of the $\mathrm{Pd}-\mathrm{Ag}$ layer (dark grey) on alumina porous support is shown in Fig. 8. The Pd-Ag membrane thickness is around $3.6 \mu \mathrm{m}$. We assume that E54 and E56 membranes are also $3.6 \mu \mathrm{m}$, since they were prepared with the same procedure as E62.

In addition, an EDX analysis was performed at the points marked in Fig. 8 and the results have been summarized in Table 4.

\section{XRD}

Two samples of the E62 membrane were analyzed by XRD and the resulting spectra are presented in Fig. 9. It can be seen that

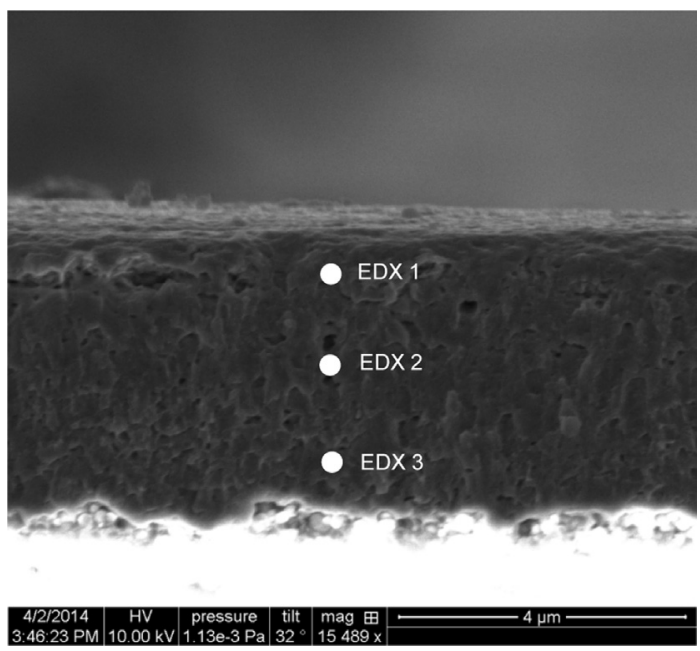

Fig. 8 - Pd-Ag layer on alumina $100 \mathrm{~nm}$ pore size (E62 membrane). 
Table 4-EDX analysis of a cross section of the membrane layer (E62 membrane).

\begin{tabular}{lcc} 
EDX position & Pd (wt\%) & Ag (wt\%) \\
\hline Point 1 & 86.2 & 13.9 \\
Point 2 & 84.5 & 15.5 \\
Point 3 & 86.1 & 13.9 \\
\hline
\end{tabular}

Pd and Ag were well alloyed, confirming that the annealing process performed is suitable. The crystalline structure of $\mathrm{Pd}-\mathrm{Ag}$ alloy was face-centered cubic (FCC) and its lattice constant was $3.903 \AA$ ("a”).

\section{Results on membranes performance and sealing stability}

Long-time permeation measurements of E15 membrane Long-time measurements for $48 \mathrm{~h}$ at $380-400{ }^{\circ} \mathrm{C}$ and 2 bar pressure difference were carried out to ensure stable membrane performance before carrying out the experiments to determine the membrane permeation parameters (the pre-exponential factor and activation energy). The hydrogen/nitrogen ideal perm-selectivity of the E15 membrane is shown in Fig. 10.

The hydrogen permeance increases for the E15 membrane during the first few hours until it reaches a stable value, which is also reported in literature for Pd-membranes [15]. It is reported in literature, that mainly two effects can responsible for the observed activation of the membranes [16]. First, there is the effect of surface contamination which can block the active sites on Pd layers for hydrogen transport. A second effect is considered as the induction period, which is related to the lattice rearrangements of Pd during hydrogen transport through the membrane.

\section{Thermal cycling experiments for E15 membrane}

To ensure that heating up and cooling down has no influence on the performance of the sealing and the membrane permeance, the E15 membrane performance was evaluated for several thermal cycles (Fig. 11) after previous long term permeation tests and found to be quite stable.

For the E15 membrane, some small fluctuations in the nitrogen permeance can be discerned, related to the very low

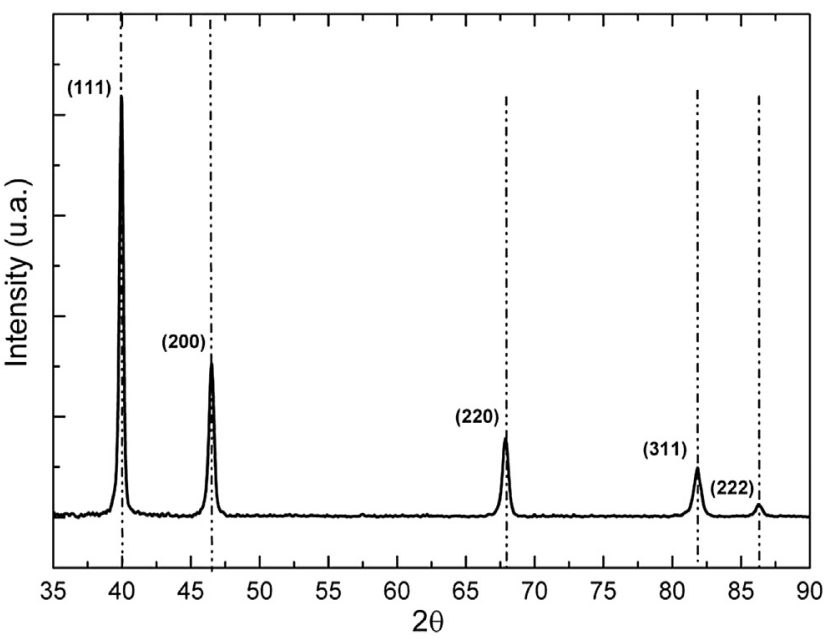

Fig. 9 - XRD spectra of E62 membrane (annealed Pd-Ag supported membrane).

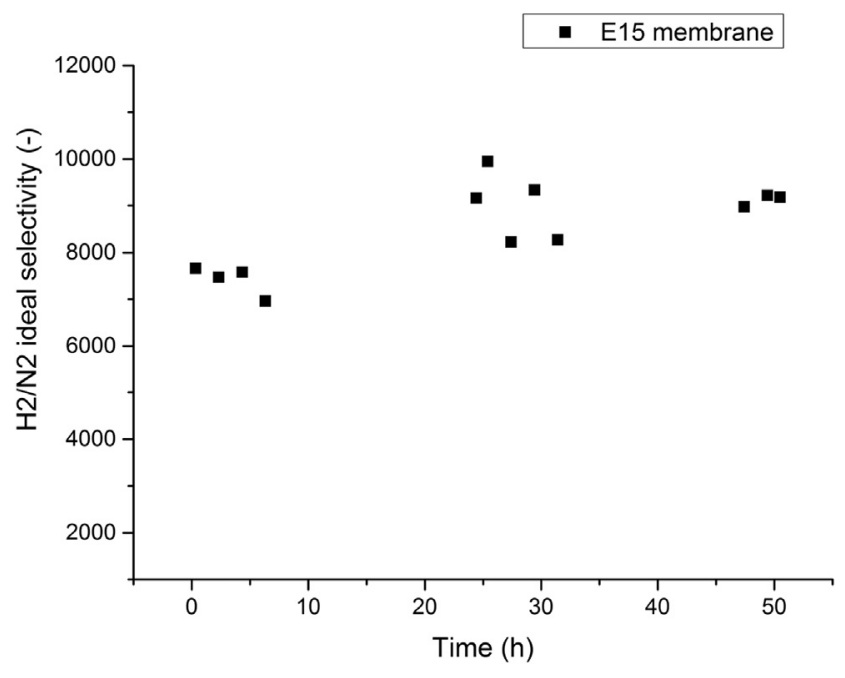

Fig. $10-\mathrm{H}_{2} / \mathrm{N}_{2}$ ideal perm-selectivity of E15 membrane during $48 \mathrm{~h}$ experiment at $380-400{ }^{\circ} \mathrm{C}$ and 2 bar of pressure difference.

nitrogen flow rates (less or close to $0.2 \mathrm{ml} / \mathrm{min}$ ), where the film flow meter could not be used for all measurements because the minimal detectable flow rate is $0.2 \mathrm{ml} / \mathrm{min}$.

\section{Determination of membrane parameters}

After the long-term measurements and the cycling experiments, the membranes were tested at different temperatures and pressures under $\mathrm{N}_{2}$ and $\mathrm{H}_{2}$. Table 5 shows the $\mathrm{N}_{2}$ permeance for the E15 membrane as a function of temperature and partial pressure difference across the membrane. Because the $\mathrm{N}_{2}$ flow rate is very low for E15, it could only be detected at pressure differences above about 4 bar, which is the maximum pressure difference available in the test setup...

Results for the hydrogen permeation experiments are shown in Fig. 12. The permeation of hydrogen is increasing with increasing transmembrane partial pressure difference. The E15 membrane exhibits an almost perfect linear behavior

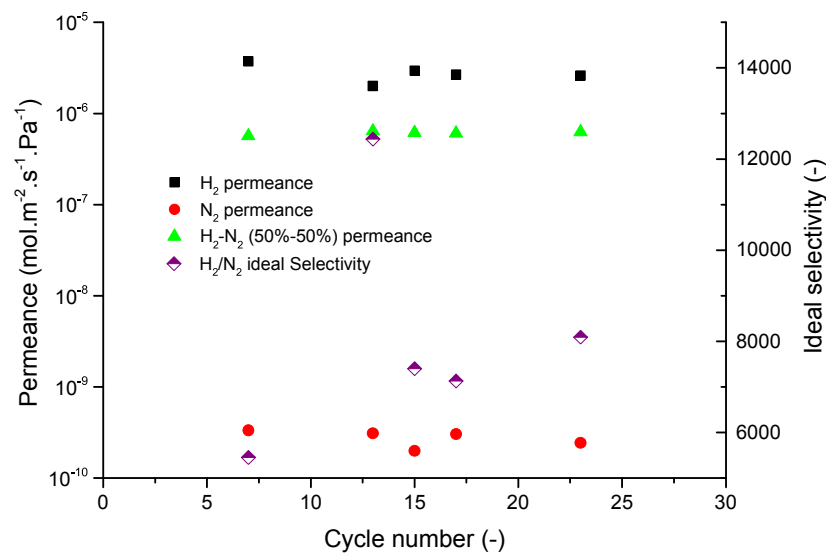

Fig. 11 - Performance of the E15 membrane with several thermal cycles after long term permeation tests (each thermal cycle indicates one heating-up and cooling-down step; from room temperature to $400^{\circ} \mathrm{C}$ ). 
Table $5-\mathrm{N}_{2}$ permeance for the $\mathrm{E} 15$ membrane at different temperatures and transmembrane pressure differences.

\begin{tabular}{lcc}
$\begin{array}{l}P_{\text {eff }} \text { retentate } \\
\text { (bar) }\end{array}$ & $\begin{array}{c}\text { Temperature } \\
\left({ }^{\circ} \mathrm{C}\right)\end{array}$ & $\begin{array}{c}\text { Permeance } \\
\left(10^{-10} \mathrm{~mol} \mathrm{~m}^{-2} \mathrm{~s}^{-1} \mathrm{~Pa}^{-1}\right)\end{array}$ \\
\hline 4.16 & 309 & 3.1 \\
4.16 & 348 & 2.8 \\
4.15 & 397 & 3.1 \\
4.08 & 449 & 2.6 \\
\hline
\end{tabular}

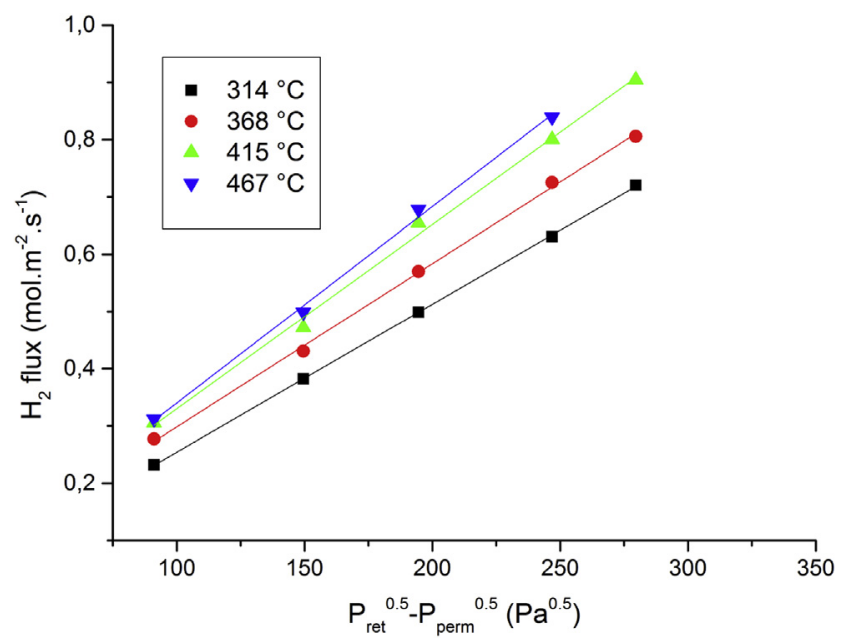

Fig. $12-\mathrm{H}_{2}$ flux versus $\mathrm{H}_{2}$ pressure difference at different temperatures for the E15 membrane.

for the exponential factor $n=0.5\left(R^{2}>0.999\right)$, which is typical for $\mathrm{Pd}-\mathrm{Ag}$ membranes at low pressures if bulk-diffusion through the membrane is the rate limiting step [17]. The activation energy of the membrane $\left(E_{a, \mathrm{Pd}}\right)$ was determined at $7.8 \mathrm{~kJ} / \mathrm{mol}$.

Table 6 compares permeation parameters for different membranes reported in the literature with the membrane used in this work.

Tests at WGS conditions

The E15 membrane performance was also investigated at WGS conditions (see Table 2) measuring the $\mathrm{H}_{2}$ permeance of the membranes before and after exposing the membrane to the WGS gas mixture at different pressure differences (see Fig. 13).

In contrast with the pure gas experiments, the flux does not show a linear dependency on the partial pressure difference and indicates a concentration polarization effect (i.e. external mass transfer resistances). At higher pressure differences the flux through the membranes is higher and the effect of concentration polarization will more pronounced.

The $\mathrm{H}_{2}$ and $\mathrm{N}_{2}$ permeances of the E15 membrane before and after exposure to the WGS gas mixture is presented in Table 7, and the results confirm that the performance of the membrane (and the sealing) is not affected under WGS conditions.

Tests under fluidization conditions

To check the performance of the membranes under fluidization conditions the membranes were tested for long time in the bubbling fluidization regime. The characteristics of the materials used for the fluidization tests have been listed in Table 8:

Firstly, the E15 membrane was tested in a fluidized bed (\#1) and the results showed a sharp drop in the performance of the membrane after several minutes. The nitrogen and hydrogen permeance was measured during $26 \mathrm{~h}$ until the membrane showed nearly constant flow for both, hydrogen and nitrogen (Fig. 14). The fluidization seems to affect the performance of the membrane significantly. The Nitrogen permeance increased and the hydrogen permeance decreased. After $20 \mathrm{~h}$ of fluidization, the membrane showed stable behavior. Flushing the reactor with air (to remove possible contamination on the membrane surface), the hydrogen permeance could be increased, but only for a few minutes. After the fluidization tests, the membrane showed the same low permeance as before flushing with air.

The permeate flux as a function of the partial pressure difference is shown in Fig. 15a for the empty reactor and fluidized bed cases. The permeance under fluidization conditions with bed \#1 (after $30 \mathrm{~h}$ of fluidization conditions) has decreased a factor 14 compared to an empty reactor (tube) as shown in the Fig. $15 \mathrm{~b}$.

There are different phenomena that could have caused the observed loss of performance. First of all, as described by Dang et al. [23], when small particles are used in the fluidized bed

\section{Table 6 - Comparison of different Pd based membranes reported in literature with the E15 membrane.}

\begin{tabular}{|c|c|c|c|c|c|c|c|}
\hline \multirow[t]{2}{*}{$\begin{array}{l}\text { Membrane } \\
\text { material }\end{array}$} & \multirow[t]{2}{*}{$\begin{array}{l}\text { Preparation } \\
\text { method }\end{array}$} & $\begin{array}{l}\text { Selective layer } \\
\text { thickness }\end{array}$ & $\mathrm{T}$ & Permeance $\mathrm{H}_{2}$ & Permeability $\mathrm{H}_{2}$ & Ideal selectivity & Ref \\
\hline & & {$[\mu \mathrm{m}]$} & {$\left[{ }^{\circ} \mathrm{C}\right]$} & $\begin{array}{c}{\left[10^{-8} \mathrm{~mol} /\right.} \\
\left.\mathrm{m}^{2} \mathrm{~s} \mathrm{~Pa}\right]^{\mathrm{a}}\end{array}$ & $\begin{array}{c}{\left[10^{-13} \mathrm{~mol} \mathrm{~m} /\right.} \\
\left.\mathrm{m}^{2} \mathrm{~s} \mathrm{~Pa}\right]\end{array}$ & - & - \\
\hline $\mathrm{Pd}-\mathrm{Au} / \mathrm{YSZ} / \mathrm{PSS}$ & ELP & 2.3 & 400 & 710 & 160 & $82,000\left(\mathrm{H}_{2} / \mathrm{N}_{2}\right)$ & [18] \\
\hline $\mathrm{Pd}-\mathrm{Au} / \mathrm{Al}_{2} \mathrm{O}_{3}$ & ELP & $2-3$ & 500 & 620 & 160 & $1400\left(\mathrm{H}_{2} / \mathrm{N}_{2}\right)$ & [19] \\
\hline $\mathrm{Pd}-\mathrm{Ag} / \mathrm{PSS}^{\mathrm{b}}$ & PVD-MS & 2.8 & 400 & 1500 & 420 & $2900\left(\mathrm{H}_{2} / \mathrm{N}_{2}\right)$ & [20] \\
\hline $\mathrm{Pd}-\mathrm{Au}-\mathrm{Pt}^{\mathrm{b}}$ & PVD-MS & 25 & 400 & 54 & 130 & - & [21] \\
\hline Pd/Inconel & ELP & 7 & 450 & 96 & 67 & $4500\left(\mathrm{H}_{2} / \mathrm{He}\right)$ & [22] \\
\hline $\mathrm{Pd}-\mathrm{Ag} / \mathrm{Al}_{2} \mathrm{O}_{3}$ & ELP & 3.2 & 400 & 310 & 100 & $8000-10,000\left(\mathrm{H}_{2} / \mathrm{N}_{2}\right)$ & This work \\
\hline
\end{tabular}




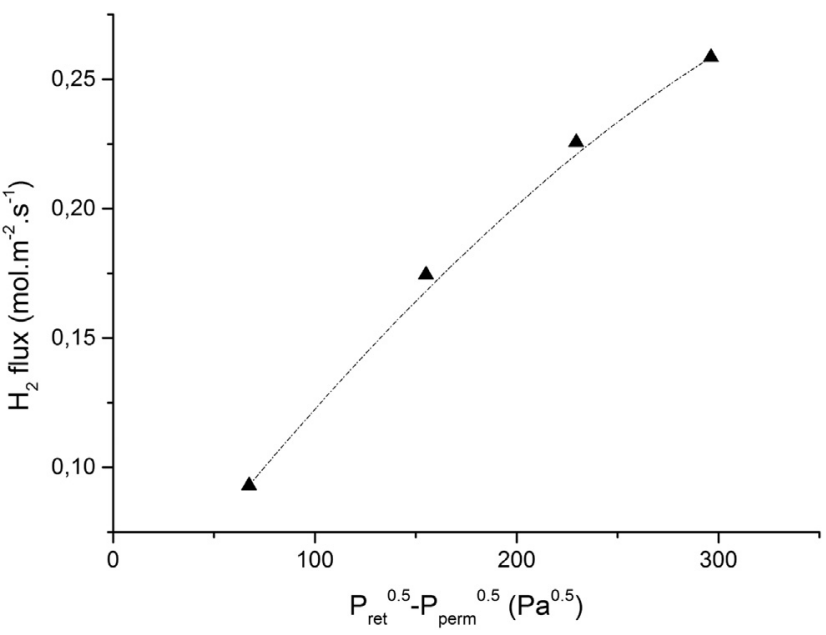

Fig. 13 - Performance of the E15 membrane at WGS conditions at different pressure differences (feed composition listed in Table 2).

membrane reactor, the extraction of a large amount of gas may lead to the formation of densified zones close to the membranes. It is possible that these densified zones have created additional mass transfer limitations for hydrogen permeation. However, as the strong decrease in flux is observed also when using pure hydrogen flow, the densification of the bed around the membranes cannot be the only cause for the loss of performance described above. Another possible phenomenon occurring in the fluidized bed membrane reactor is a possible erosion of the palladium layer, which would be detrimental for the performance of the membranes [1]. However, erosion of the Pd layer should lead to an increase in hydrogen flux rather than a (strong) decrease.

A possible phenomenon that could explain the decrease in hydrogen flux is a possible chemical interaction between the palladium and (some components of the catalyst used in the tests. In fact, previous tests with Pd membranes on alumina, have shown strong chemical interaction (and eventually
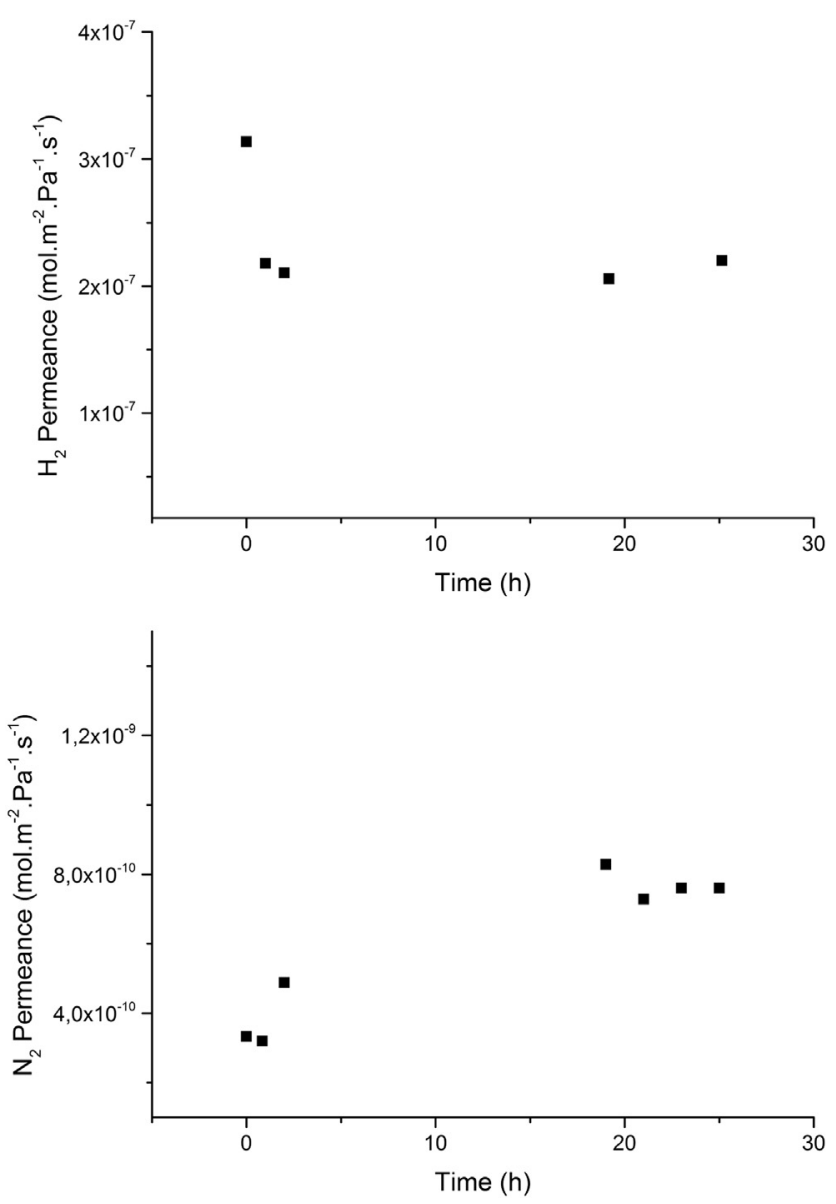

Fig. $14-\mathrm{N}_{2}$ and $\mathrm{H}_{2}$ permeances at fluidization (bed \#1) for E15 membrane $\left(400^{\circ} \mathrm{C}\right)$.

alloying) of Pd with alumina at higher temperatures [24]. Most probably, a similar kind of interaction may have occurred with the catalyst used in these tests but at lower temperatures.

To demonstrate this, new tests have been carried out at lower pressure to minimize the flux of hydrogen through the

Table 7 - Permeation of $\mathrm{H}_{2}$ and $\mathrm{N}_{2}$ before and after exposure to a WGS gas mixture (400 ${ }^{\circ} \mathrm{C}$ ).

\begin{tabular}{llcc} 
Gas & \multicolumn{1}{c}{ Condition } & $\begin{array}{c}P_{\text {ret }}-P_{\text {perm }} \\
(\text { bar })\end{array}$ & $\begin{array}{c}\text { Permeance } \\
\left(\mathrm{mol} \mathrm{m}^{-2} \mathrm{~s}^{-1} \mathrm{~Pa}^{-1}\right)\end{array}$ \\
\hline $\mathrm{N}_{2}$ & Before WGS mixture & 4.15 & $2.21 \cdot 10^{-10}$ \\
& After WGS mixture & 5.18 & $2.32 \cdot 10^{-10}$ \\
$\mathrm{H}_{2}$ & Before WGS mixture & 2.08 & $3.58 \cdot 10^{-6}$ \\
& After WGS mixture & 2.12 & $3.48 \cdot 10^{-6}$ \\
\hline
\end{tabular}

Table 8 - Characteristics of the particle beds used in the fluidization tests.

\begin{tabular}{|c|c|c|c|c|}
\hline \multirow[t]{2}{*}{ Bed } & \multicolumn{2}{|c|}{ Catalyst } & \multicolumn{2}{|c|}{ Filler } \\
\hline & Material & Particle size $(\mu \mathrm{m})$ & Material & Particle size $(\mu \mathrm{m})$ \\
\hline \#1 & $0.16 \% \mathrm{Re} 0.34 \% \mathrm{Pt} 6 \% \mathrm{Ce} / \mathrm{TiO}_{2}$ & 75-106 & $\mathrm{TiO}_{2}$ & $100-125$ \\
\hline \#2 & Noble based CPO cat. $^{\mathrm{a}}$ & $50-75$ & $\mathrm{Al}_{2} \mathrm{O}_{3}$ & 104 \\
\hline
\end{tabular}




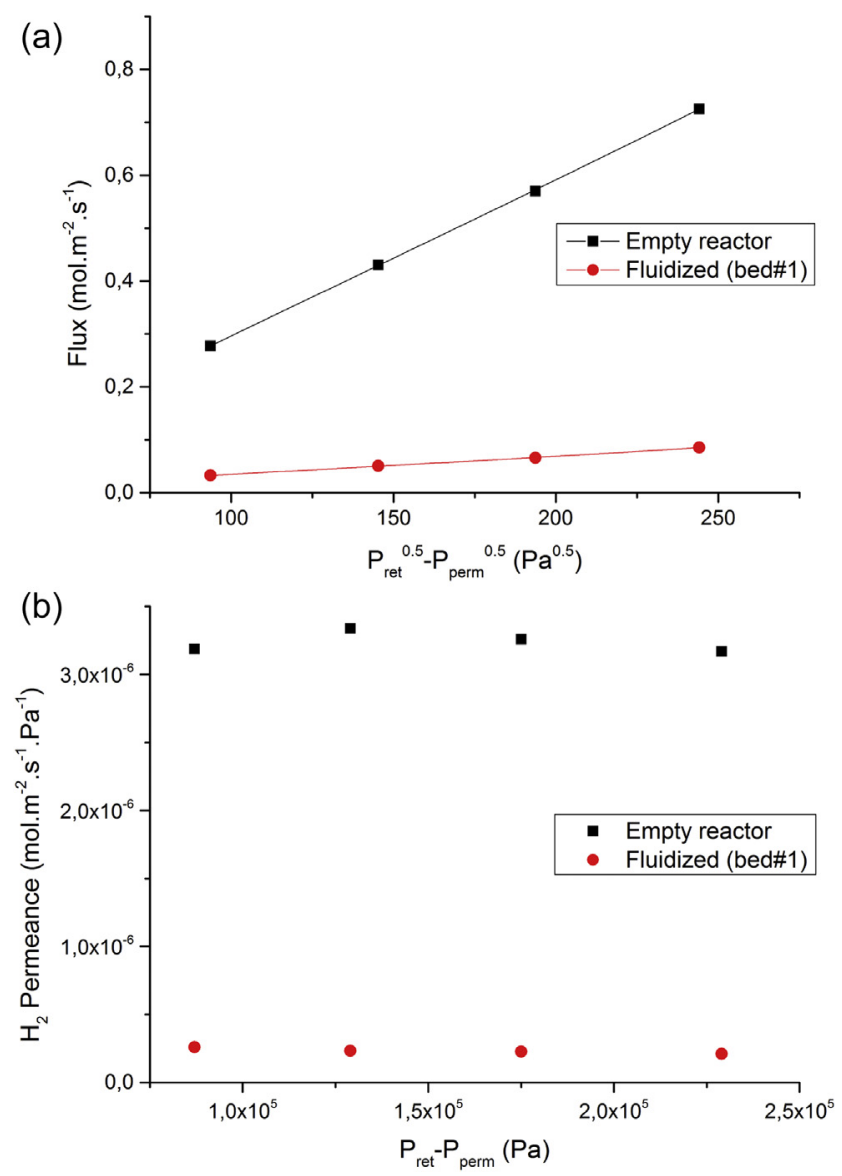

Fig. 15 - (a) $\mathrm{H}_{2}$ Flux at different pressure differences and (b) $\mathrm{H}_{2}$ permeance under fluidization conditions (bed \#1) in comparison with the case in an empty reactor for the E15 membrane $\left(400{ }^{\circ} \mathrm{C}\right)$.

membrane and thus rule out the formation of densified zones as a possible cause [23].

Fig. 16a shows the results of the long term permeation experiment of membrane E54 under relatively low hydrogen flux. As can be seen, the hydrogen permeance decreases with a sharp slope during the first $20 \mathrm{~h}$ of the tests also for this membrane under low hydrogen flux conditions. After this time a stable membrane performance could be achieved. A comparison of the performance of membrane E54 after different tests is reported in Fig. 16b. The membrane performance loss is about 10 times at stable fluidization conditions in comparison to the tests before the fluidization (permeation tests with empty tube). These tests clearly indicate that the possible densification of particles around the membrane cannot be the cause and thus further tests were carried out to elucidate the reason for this behavior.

Fig. 17 shows the E54 membrane before and after the fluidization tests. As can be seen the membrane surface has changed due to the fluidization tests and the interaction with the catalyst and the inert particles. The membrane was cleaned with pressurized air and demineralized water in order to clean the surface without damaging it. However, no changes in the performances are observed after cleaning of

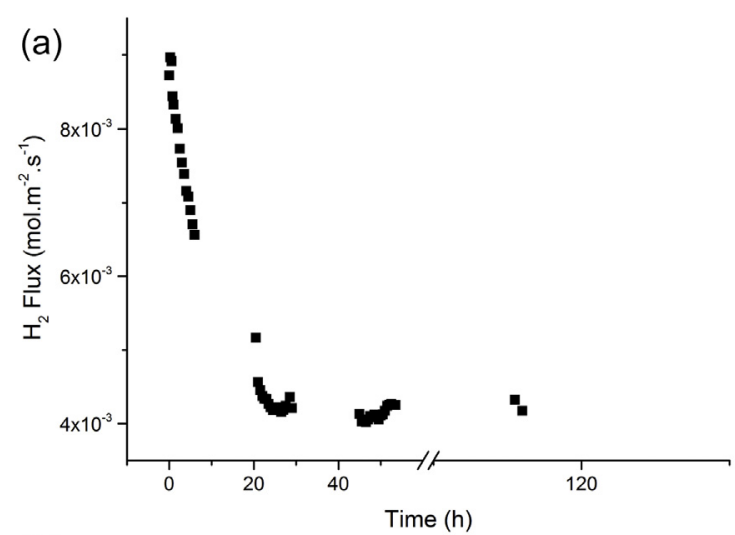

(b)

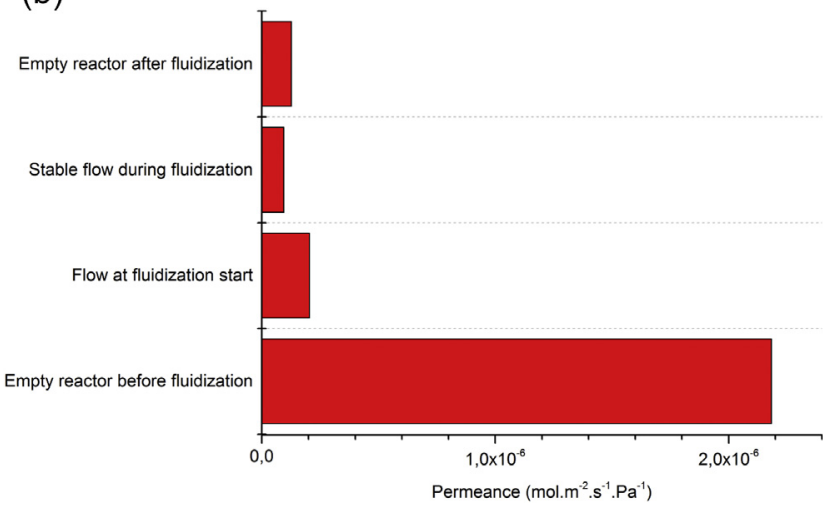

Fig. 16 - (a) $\mathrm{H}_{2}$ flow evolution of E54 membrane in bed \#1 fluidization and at low pressure difference and (b) comparison with results before fluidization $\left(400{ }^{\circ} \mathrm{C}\right), \mathrm{H}_{2}$ flow rate in the feed up to $1100 \mathrm{ml} / \mathrm{min}$.

the surface. This suggests that there is a strong interaction on the membrane surface with (components of) the catalyst.

Additional fluidization tests were carried out with the new membrane E56. Firstly, this membrane was protected with a thin layer of glass wool before the fluidization tests. This kind of tests were performed to understand whether the interaction between the particles and the membranes are enhanced by attrition. Additionally, before testing the WGS catalyst with the new membrane, another catalyst has been used (bed \#2) for fluidization tests, as this material was already been used for steam methane reforming in fluidized bed membrane

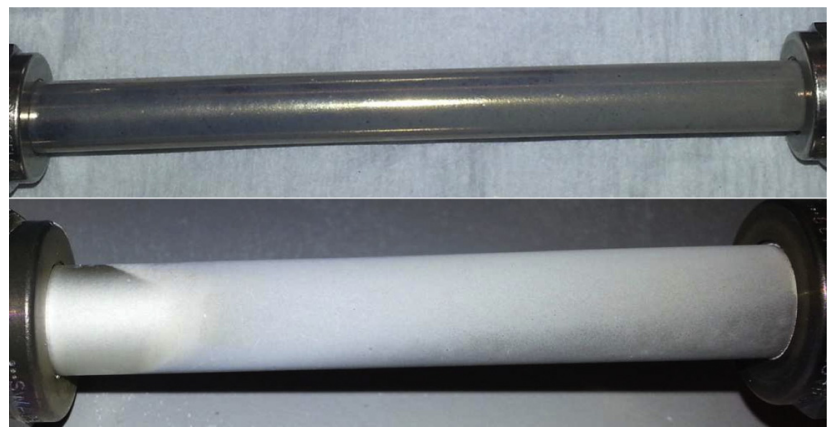

Fig. 17 - E54 membrane before and after fluidization tests with bed \#1. 
reactors without detrimental effects to the membrane performance [25]. After a successful test with the glass wool, the membrane E56 was tested without the glass wool protection (thus in direct contact with bed material \#2). In the final test E56 was tested with a protective layer of glass wool together with bed \#1 under fluidization conditions (bubbling fluidization regime).

Fig. 18 shows the results of the performance of the E56 membrane for different test conditions:

a) Without bed before fluidization

b) With glass wool

c) Empty reactor after fluidization test

d) With Bed \#2 \& glass wool

e) With Bed \#2

f) With Bed \#1 \& glass wool

The figure shows that the membrane permeance increased between the first test (empty reactor case) and the test with glass-wool protection. No decrease of permeance has been detected as the porous glass wool does not induce any additional mass transfer limitation. The reason for the increase of permeance during the tests is the activation of the membrane being exposed to hydrogen at high temperature.

The test with bed material \#2 and the protective layer of glass wool shows no decrease in permeance. During the almost $6 \mathrm{~h}$ of test it can be seen that the permeance of the membrane was even slightly increasing over time, again related to the activation of the membrane. Wang et al. [16] reported a reactivation time of about $800 \mathrm{~min}$ of $\mathrm{H}_{2}$ exposure before the membrane reached its original value for hydrogen permeance again. After this test, the protective layer of glass wool was removed and the membrane was tested during $48 \mathrm{~h}$ under fluidization conditions with direct contact between the bed material and the membrane. The results obtained show that the membrane performance is not affected by fluidization when bed material \#2 was used, in contrast to the tests performed with E54 using bed material \#1. This confirms the assumption that the catalyst particles or the filler particles from bed \#1 are the cause of the performance loss of the

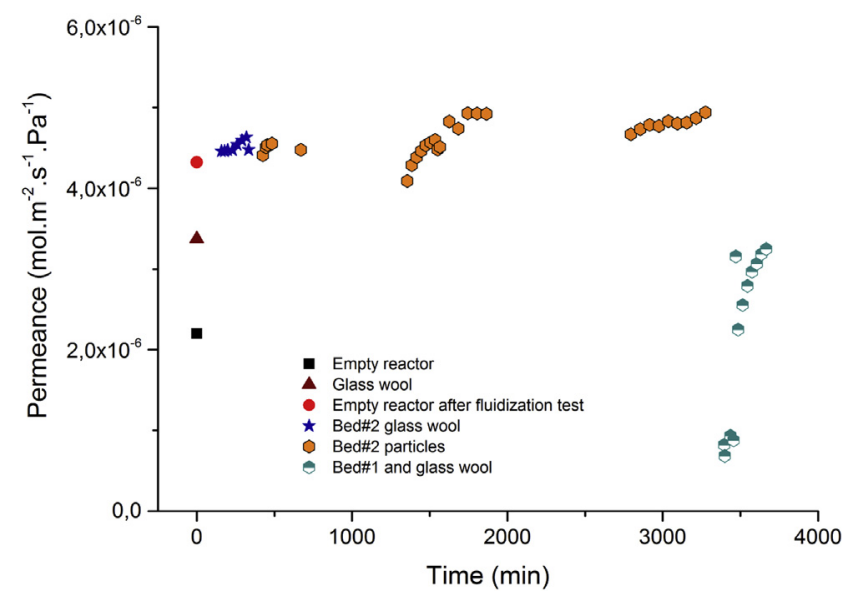

Fig. 18 - E56 membrane performance in different test configurations $\left(400{ }^{\circ} \mathrm{C}\right) \mathrm{H}_{2}$ flow rate in the feed up to $1100 \mathrm{ml} / \mathrm{min}$. membranes under fluidization conditions. Mechanical stresses due to the fluidization regime has been found not to be responsible for any performance loss of the membrane.

To finalize the study, membrane E56 was protected with glass wool and used under fluidization conditions with bed material \#1. It can be observed that the hydrogen permeance was lower than for any of the other cases. After exposing the membrane to air (to remove possible contaminations) the permeance starts to increase. After $6.5 \mathrm{~h}$ of test under fluidization conditions, however, the hydrogen permeance was not yet at the same level as before this last test. So, most probably there is an interaction with the particles even if the membrane is protected by glass wool. After removing the glass wool, it was indeed observed that some particles had reached the membrane surface and probably interacted with the membrane, thereby decreasing its permeance. These tests indicate that in case of reactive particles, a better protection of the membrane should be adopted, while for inert particles, the membrane can be safely used in fluidized beds without any protection.

Fig. 19a shows the nitrogen permeance of membrane E56 measured over time during the tests with bed material \#2 (without glass wool). As can be observed, the permeance of
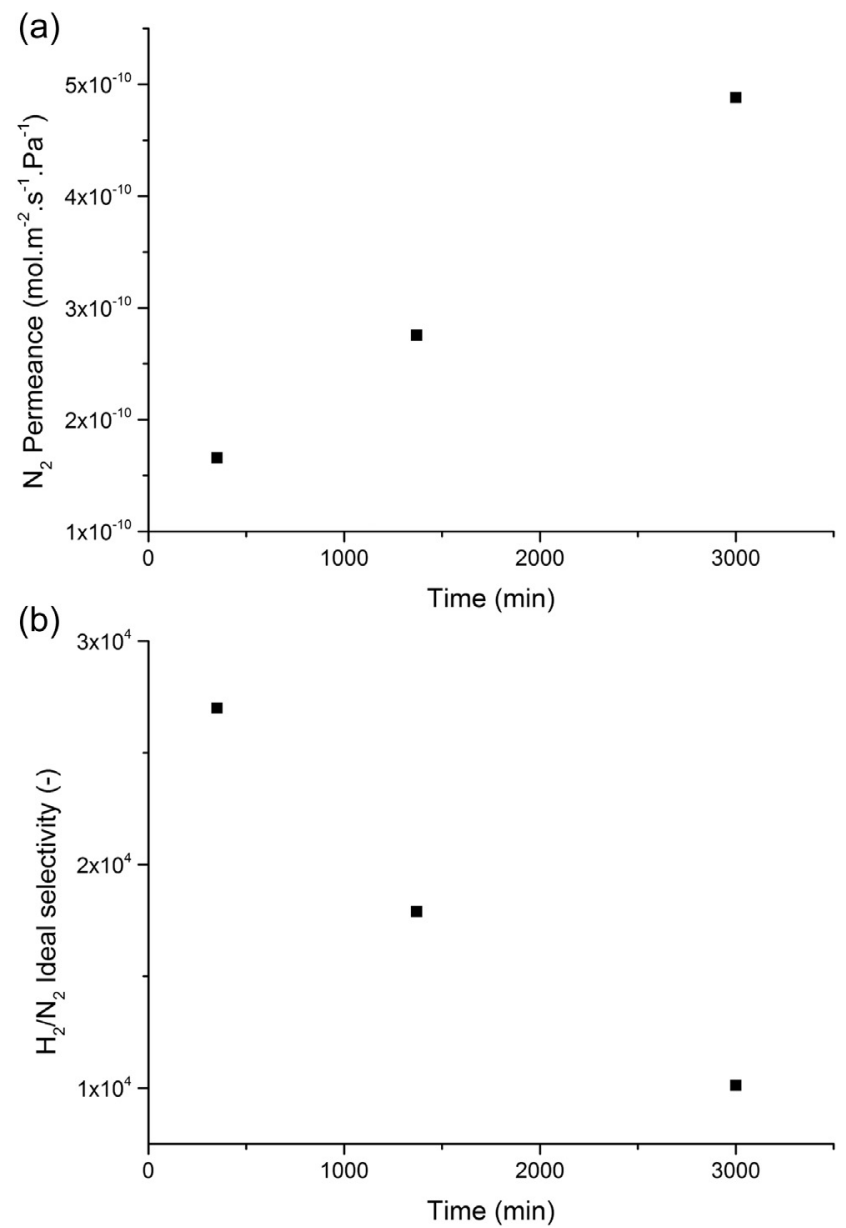

Fig. 19 - a) $\mathrm{N}_{2}$ permeance and b) $\mathrm{H}_{2} / \mathrm{N}_{2}$ ideal permselectivity for the E56 membrane during $48 \mathrm{~h}$ fluidization test with bed $\# 2\left(400{ }^{\circ} \mathrm{C}\right)$ gas flow rate $\left(\mathrm{H}_{2}\right.$ or $\left.\mathrm{N}_{2}\right)$ in the feed up to $1100 \mathrm{ml} / \mathrm{min}$. 
nitrogen increases during the time of fluidization, which leads to a loss of selectivity (see Fig. 19b). However, after the fluidization tests the selectivity was still above 10,000. A more detailed study is required to assess the influence of fluidization on the sealing material.

Mass transfer limitations and CO poisoning effect

It is well known that the higher the membrane permeation flux, the more important other mass transfer limitations may become. In this section external mass transfer limitations (concentration polarization) and mass transfer limitations due to possible $\mathrm{CO}$ poisoning of the membrane surface are further investigated. Different tests were carried out at different $\mathrm{H}_{2} / \mathrm{N}_{2}$ ratios. The results for the hydrogen flux at different $\mathrm{H}_{2} / \mathrm{N}_{2}$ mixtures are shown in Fig. 20.

The hydrogen flux through the membrane is plotted as a function of the partial pressure difference of hydrogen (inlet conditions). At the same partial pressure difference the driving force for the permeation for all experiments is the same. The results show that the hydrogen flux decreases when the concentration of hydrogen decreases in the feed gas stream (at the same driving force over the membrane). This behavior confirms that external mass transfer limitations (concentration polarization) are prevailing using gas mixtures, as was anticipated for highly permeable membranes.

These external mass transfer limitations (due to gas phase diffusion) could be decreased in case of fluidization, as the additional mixing induced by the solids circulation patterns in the bubbling (and turbulent) fluidization regime increases the local driving force for permeation. Indeed, comparing the experiments with fluidized particles in the reactor and the experiments with an empty reactor it could be observed that the hydrogen permeance was higher for the fluidized bed cases. This effect can be clearly seen from Fig. 21, showing a comparison between two experiments carried out at the same conditions (temperature, feed flow rate and composition and transmembrane pressure difference), for an empty membrane reactor and for the fluidized bed membrane reactor. These results confirm once more that the fluidized bed membrane

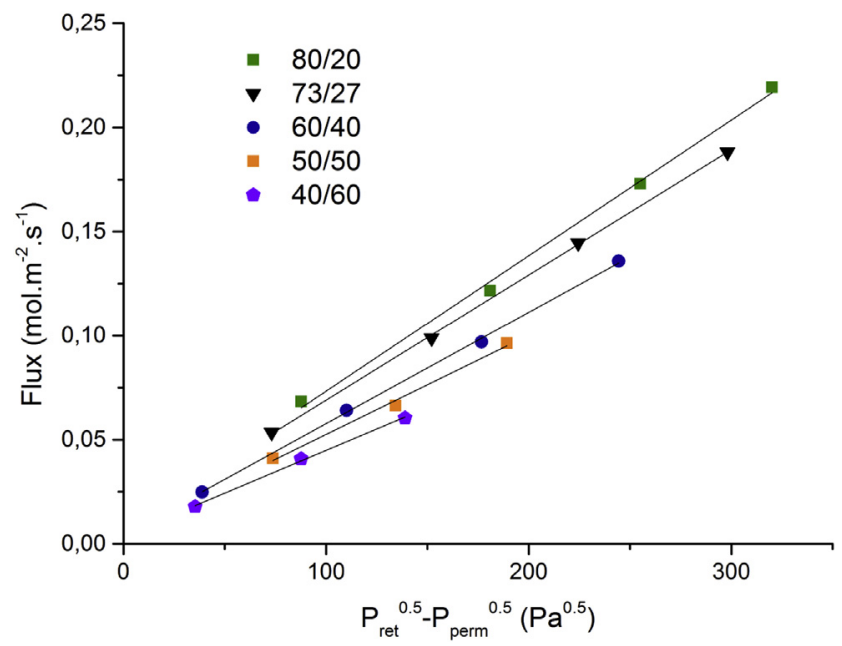

Fig. 20 - Hydrogen permeate flux of E56 membrane at different $\mathrm{H}_{2} / \mathrm{N}_{2}$ feed compositions $\left(400{ }^{\circ} \mathrm{C}\right)$ gas flow rate in the feed up to $1500 \mathrm{ml} / \mathrm{min}$.

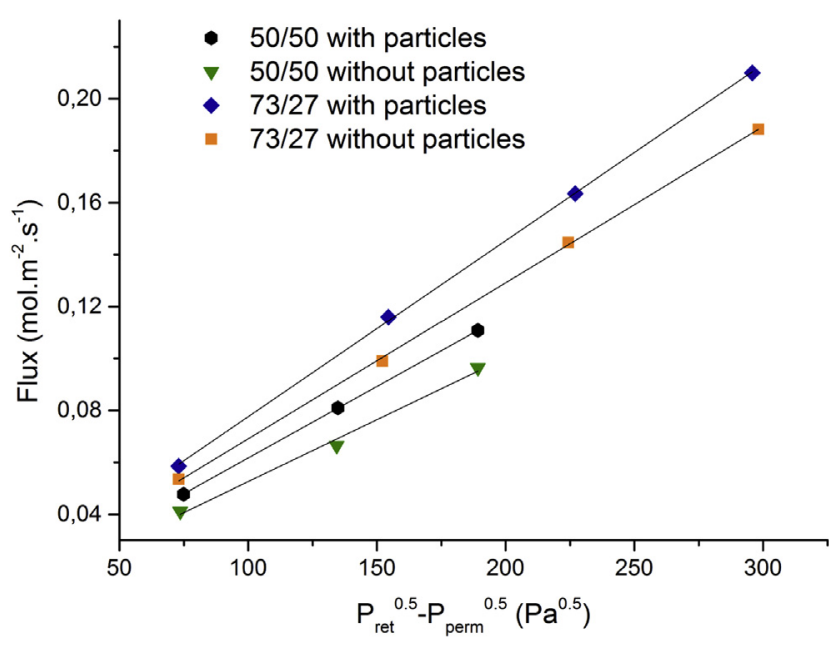

Fig. $21-\mathrm{H}_{2}$ flux through the E56 membrane for the empty reactor and the fluidized bed reactor for different feed compositions $\left(400{ }^{\circ} \mathrm{C}\right)$ gas flow rate in the feed up to $1500 \mathrm{ml} / \mathrm{min}$.

reactor is a preferred reactor concept for highly permeable membranes.

As far as the membrane poisoning is concerned, it is well known that $\mathrm{CO}$ can block the active sites of the membrane (CO poisoning effect) and deteriorate the performance of the membranes [26]. This effect can be more pronounced for the highly permeable membranes. The CO poisoning effect was measured in a gas mixture containing $80 \%$ of hydrogen and increasing the amount of CO from 0 to $15 \%$ in steps of $5 \%$. The results obtained can be seen in Fig. 22.

The effect of $\mathrm{CO}$ poisoning detected for a maximum amount of $15 \%$ CO in the feed gas mixture, is quite low (as expected considering the relatively high temperature). However, this effect is also not negligible, as the permeance of

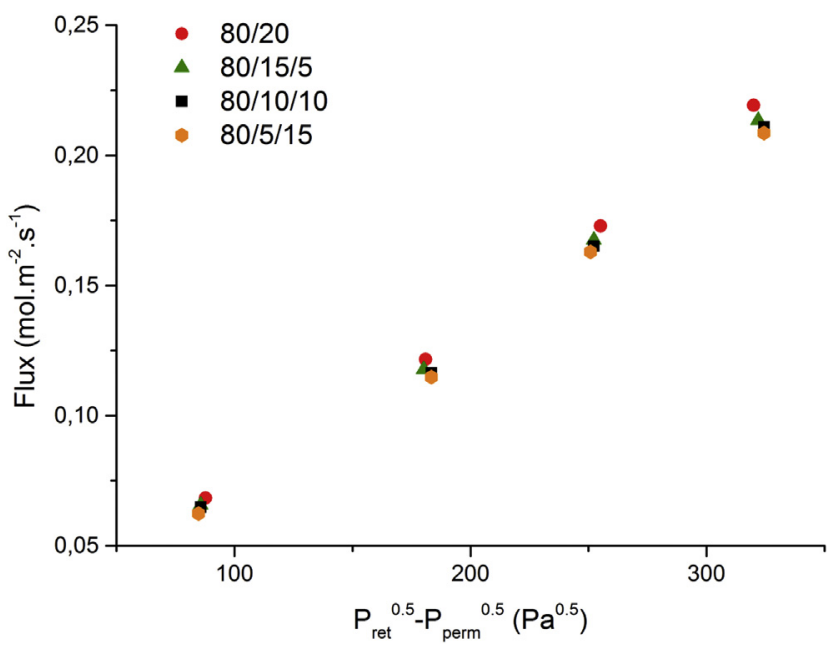

Fig. 22 - Effect of CO poisoning on hydrogen flux of E56 membrane $\left(400{ }^{\circ} \mathrm{C}\right.$, the legend indicates the feed composition $\mathrm{H}_{2} / \mathrm{CO} / \mathrm{N}_{2}$ ) gas flow rate in the feed up to $1500 \mathrm{ml} / \mathrm{min}$. 


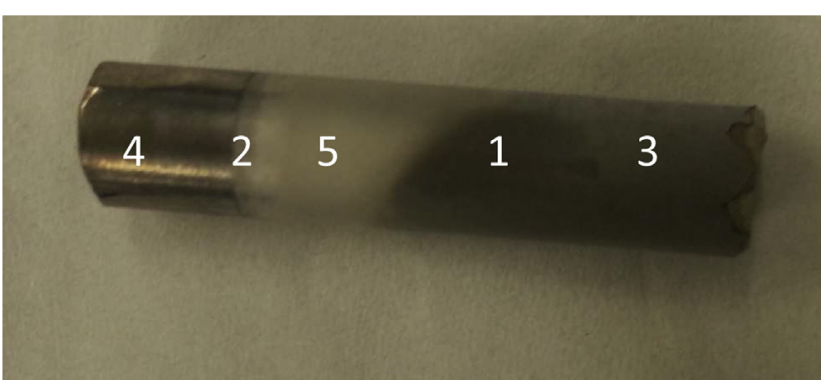

Fig. 23 - Post-mortem E54 sample used for the XPS analysis: (1) Membrane surface was carefully cleaned with paper to remove "dust"; (2) Area that is between the Swagelok ${ }^{\circledR}$ connector and the membrane without graphite; (3) Surface which was under fluidization without removing the "dust"; (4) Area where the graphite sealing was placed; (5) surface with less signs of interaction (defined hereafter as stagnant zone).

hydrogen decreased about $7 \%$ for $15 \%$ of CO in the feed gas stream. At higher temperatures this effect should be less significant, since the poisoning effect of $\mathrm{CO}$ is dependent on temperature and it is higher at lower temperatures [27].

\section{Post-mortem characterization results of $\mathrm{Pd}-\mathrm{Ag}$ supported membranes}

\section{XPS analysis of membrane E54}

Experimental observations on the membranes E54 and E56 confirmed that either the filler $\left(\mathrm{TiO}_{2}\right)$ or the catalyst $(0.16 \%$ $\mathrm{Re} 0.34 \% \mathrm{Pt} 6 \% \mathrm{Ce} / \mathrm{TiO}_{2}$ ) from bed material \#1 were responsible for the loss of the hydrogen permeance during the fluidization tests. Therefore, XPS analysis was carried out on membrane E54 to elucidate the reason for the loss of permeance.

Fig. 23 shows the sample of the E54 membrane that was used for the XPS analysis, which represents approximately half of the membrane. As a reference, one piece of E54 was cut before the test, which has also been analyzed with XPS. The XPS measurements were carried out without etching, which makes the results being representative for the first $10 \mathrm{~nm}$ of the membrane surface. The area of each measurement was about $400 \mu \mathrm{m}$ in diameter.

The results of the XPS analysis have been summarized in Table 9.

As can be seen in the results of Table $9, \mathrm{Ti}$ and $\mathrm{O}$ are found in high amounts on the membrane surface $(1,3)$, where the effect of fluidization was more pronounced. Comparing these results to the stagnant zone (5), it is evident that this zone is nearly free of $\mathrm{Ti}$ and completely free of $\mathrm{O}$ which implies that the interaction between the membrane and the solids occurs where there is more contact between the two. In the part where the Swagelok ${ }^{\circledR}$ fitting is close to the membrane a significant amount of sulfur was found, which could possibly have been released by the Swagelok ${ }^{\circledR}$ fitting due to reaction with gases under high temperature, since sulfur is present in the stainless steel parts of Swagelok ${ }^{\circledR}$ [28].

The results for the measurements for the reference membrane show that there is no $\mathrm{Ti}$ and no $\mathrm{O}$ before the fluidization tests, as expected. It is interesting to mention that no Ag was detected on the surface of the membrane in the XPS analysis, which is probably related to the measuring method. XPS with etching would lead to a correct detection of $\mathrm{Ag}$ and $\mathrm{Pd}$, but would lead to an incorrect detection of $\mathrm{Ti}$ and $\mathrm{O}$ that are the components leading to a decrease of permeance according to our previous observations.

A reason for the high amount of carbon found in the sealing part is the graphite ferrule attached to the membrane surface. Nevertheless, a significant amount of carbon is also detected for the samples under fluidization regime due to the contamination by the paper used for cleaning the surface before the tests. In general, it can be concluded that the catalyst active species seems not to be the reason for the decrease in permeance, since no Re, Ce or Pt could be found on the membrane surface, pointing towards the support material as the cause for the decrease in membrane permeance while the main responsible seems to be the interaction of $\mathrm{Ti}$ with the palladium layer. Interaction of $\mathrm{TiO}_{2}$ and Pd was already observed by Dittmeyer and co-workers [29]. It is thus suggested to use a catalyst support based on a material that does not have interaction with palladium like alumina or zirconia-based supports. In a future work we will further investigate the interaction of the Pd-based membranes with different catalysts/supports at different operating conditions.

\section{Conclusions}

In this paper a series of thin membranes have been produced with sequential electroless plating and tested as permeators and in fluidized bed conditions. A simple technique for membrane sealing has been implemented and discussed in the paper based on standard connectors and graphite ferrules.

\section{Table 9 - Results of XPS analysis for E54.}

\begin{tabular}{|c|c|c|c|c|c|c|c|c|c|}
\hline \multicolumn{2}{|c|}{ Sample identifier } & $\operatorname{Ag} 3 d \%$ & Ce $3 d \%$ & O $1 \mathrm{~s} \%$ & $\mathrm{Pd} 3 \mathrm{~d} \%$ & S $2 p \%$ & Si $2 p \%$ & C $1 \mathrm{~s} \%$ & Ti 2p \% \\
\hline 1 & Cleaned part & 4 & 0.2 & 53.6 & 4 & 1 & 0 & 19.2 & 18.1 \\
\hline 2 & Swagelok ${ }^{(\mathbb{B}}$ part & 4.6 & 0 & 0 & 35.3 & 10.6 & 0 & 48.5 & 1.1 \\
\hline 3 & Fluidized part & 3.8 & 0.2 & 56 & 4.4 & 1.2 & 0 & 14.6 & 19.8 \\
\hline 4 & Sealing part & 0.3 & 0 & 12.2 & 2.6 & 0.3 & 0 & 84.4 & 0.2 \\
\hline 5 & Stagnant zone part & 16.2 & 0 & 0 & 55.2 & 5.7 & 0 & 21.6 & 1.3 \\
\hline 6 & Ref membrane1 & 0 & 0 & 0 & 27.7 & 2.5 & 2.7 & 67.1 & 0 \\
\hline 7 & Ref membrane2 & 0 & 0 & 0 & 28.6 & 0 & 3.3 & 68.1 & 0 \\
\hline 8 & Ref membrane3 & 0 & 0 & 0 & 28.2 & 2.5 & 3.5 & 65.9 & 0 \\
\hline
\end{tabular}


The membranes have shown very high and stable permeation rates (with high selectivities), such that external mass transfer limitations start to be a limiting factor for the hydrogen permeation. It has been demonstrated that a fluidized bed reactor can decrease the extent of external mass transfer limitations as a result of increased gas mixing.

However, the tests under fluidization conditions show that there may be an interaction between some bed materials and the membranes, which may result in a decrease in the membrane permeation. The fluidized bed reactor should thus be operated with catalyst/supports that have no interaction with the membrane such as alumina (as demonstrated in this paper) or zirconia-based supports.

\section{Acknowledgments}

The presented work is funded within DEMCAMER project as part of the European Union 7th Framework Programme (FP7/ 2007-2013) under grant agreement $n^{\circ}$ NMP3-LA-2011-262840. Note: "The present publications reflect only the author's views and the Union is not liable for any use that may be made of the information contained therein."

The authors would like to thank Joris Garenfeld for his help optimizing the graphite sealing procedure and to Rauschert Kloster Veilsdorf for providing the ceramic tubular supports and ICP-CSIC for the catalyst material (\#1). Finally, the authors would like to thank University of Basque Country (UPV-EHU) for Zabalduz scholarship program and Prof. Pedro Luis Arias.

\section{R E F E R E N C E S}

[1] Paglieri SN, Way JD. Innovations in palladium membrane research. Sep Purif Rev 2002;31:1-169.

[2] Gallucci F, Fernandez E, Corengia P, van Sint Annaland M. Recent advances on membranes and membrane reactors for hydrogen production. Chem Eng Sci 2013;92:40-66.

[3] Barbieri G, Brunetti A, Tricoli G, Drioli E. An innovative configuration of a Pd-based membrane reactor for the production of pure hydrogen: experimental analysis of water gas shift. J Power Sources 2008;182:160-7.

[4] Gallucci F, van Sint Annaland M, Kuipers JAM. Pure hydrogen production via autothermal reforming of ethanol in a fluidized bed membrane reactor: a simulation study. Int J Hydrogen Energy 2010;35(4):1659-68.

[5] Gallucci F, van Sint Annaland M, Kuipers JAM. Theoretical comparison of packed bed and fluidized bed membrane reactors for methane reforming. Int J Hydrogen Energy 2010;35(13):7142-50.

[6] Hydrogen from coal program, RD\&D plan. U.S. Dept. of Energy; 2010. p. 19.

[7] Iniotakis N, Von Der Decken CB, Fedders H, Froehling W, Sernetz F. Hydrogen permeation membrane. US Patent 4699637. 1987.

[8] Pacheco Tanaka DA, Llosa Tanco MA, Niwa S, Wakui Y, Mizukami F, Namba T, et al. Preparation of palladium and silver alloy membrane on a porous $\alpha$-alumina tube via simultaneous electroless plating. J Memb Sci 2005;247:21-7.

[9] Okazaki J, Tanaka D, Tanco M, Wakui Y, Mizukami F, Suzuki T. Hydrogen permeability study of the thin $\mathrm{Pd}-\mathrm{Ag}$ alloy membranes in the temperature range across the $\alpha-\beta$ phase transition. J Memb Sci 2006;282:370-4.
[10] Suzuki TM, Tanaka DAP. Composite palladium membranes with improved durability toward hydrogen embrittlement. In: Gorley SV, editor. Handbook of membrane research: properties, performance and applications. Nova Science Publishers, Inc; 2009. p. 1-10.

[11] Hu X, Huang Y, Shu S, Fan Y, Xu N. Toward effective membranes for hydrogen separation: multichannel palladium membranes. J Power Sources 2008;181:135-9.

[12] Quicker P, Höllein V, Dittmeyer R. Catalytic dehydrogenation of hydrocarbons in palladium composite membrane reactors. Catal Today 2000;56:21-34.

[13] Rusting F, Pex PPAC, Peters JAJ, Jong GD. Sealing socket and method for arranging a sealing socket to a tube. Eur Pat EP 1257758. 2005.

[14] Chen W, Hu X, Wang R, Huang Y. On the assembling of Pd/ ceramic composite membranes for hydrogen separation. Sep Purif Technol Mar 2010;72(1):92-7.

[15] van Berkel F, Hao C, Bao C, Jiang C, Xu H, Morud J, et al. Pdmembranes on their way towards application for $\mathrm{CO}_{2}$ capture. Energy Procedia 2013;37:1076-84.

[16] Wang W, Pan X, Zhang X, Yang W, Xiong G. The effect of coexisting nitrogen on hydrogen permeation through thin $\mathrm{Pd}$ composite membranes. Sep Purif Technol Apr 2007;54(2):262-71.

[17] Adris AM, Lim CJ, Grace JR. The fluidized-bed membrane reactor for steam methane reforming: model verification and parametric study 1997;52(10):1609-22.

[18] Hatlevik $\varnothing$, Gade SK, Keeling MK, Thoen PM, Davidson AP, Way JD. Palladium and palladium alloy membranes for hydrogen separation and production: history, fabrication strategies, and current performance. Sep Purif Tech 2010;73:59-64.

[19] Goldbach A, Xu H. High-flux $\mathrm{H}_{2}$ separation membranes from $(\mathrm{Pd} / \mathrm{Au})_{n}$ nanolayers. Int J Hydrogen Energy 2011;36:2281-4.

[20] Peters TA, Kaleta T, Stange M, Bredesen R. Development of thin binary and ternary Pd-based alloy membranes for use in hydrogen production. J Memb Sci 2011;383:124-34.

[21] Coulter KE, Way JD, Gade SK, Chaudhari S, Alptekin GO, DeVoss SJ, et al. Sulfur tolerant PdAu and PdAuPt alloy hydrogen separation membranes. J Memb Sci 2012;405-406:11-9.

[22] Ma YH. Composite Pd and Pd Alloy porous stainless steel membranes for hydrogen production and process intensification. FY 2009 [Annual Progress Report].

[23] Dang TYN, Gallucci F, van Sint Annaland M. Micro-structured fluidized bed membrane reactors: solids circulation and densified zones distribution. Chem Eng J 2014;239:42-52.

[24] Okazaki J, Ikeda T, Pacheco Tanaka DA, Llosa Tanco MA, Wakui Y, Sato K, et al. Importance of the support material in thin palladium composite membranes for steady hydrogen permeation at elevated temperatures. Phys Chem Chem Phys 2009;11:8632-8.

[25] Gallucci F, Van Sint Annaland M, Kuipers JAM. Autothermal reforming of methane in a novel fluidized bed membrane reactor. Part 1: experimental demonstration. Top Catal 2008;51:133-45.

[26] Basile A, Gallucci F. Membranes for membrane reactors. John Wiley \& sons; 2011. p. 615.

[27] Gallucci F, Chiaravalloti F, Tosti S, Drioli E, Basile A. The effect of mixture gas on hydrogen permeation through a palladium membrane: experimental studies and theoretical approach. Int J Hydrogen Energy 2007;32:1837-45.

[28] Swagelok. Stainless steel seamless tubing. February 2013. p. 1-4.

[29] Huang Y, Dittmeyer R. Preparation and characterization of composite palladium membranes on sinter-metal supports with a ceramic barrier against intermetallic diffusion. J Memb Sci 2006;282(1-2):296-310. 